CUADERNOS DE ESTUDIOS GALLEGOS, LXIV Núm. 130 (enero-diciembre 2017), págs. 431-465

ISSN: $0210-847 \mathrm{X}$

DOI: $10.3989 /$ ceg.2017.130.12

\title{
LA REUTILIZACIÓN HOTELERA DEL PATRIMONIO MONÁSTICO GALLEGO
}

\author{
Alberta Lorenzo Aspres \\ Proxecto ARGA. Arquitecturas Rehabilitadas de Galicia \\ ORCID iD: http://orcid.org/0000-0003-4366-1290
}

Copyright: (C) 2017 CSIC. Este es un artículo de acceso abierto distribuido bajo los términos de una licencia de uso y distribución Creative Commons Attribution (CC-by) España 3.0.

Cómo citar/Citation: Alberta LORENZo AsPREs, "La reutilización hotelera del patrimonio monástico gallego", Cuadernos de Estudios Gallegos, 64, núm. 130 (2017), págs. 431-465, DOI: http:// dx.doi.org/10.3989/ceg.2017.130.12 


\section{LA REUTILIZACIÓN HOTELERA DEL PATRIMONIO MONÁSTICO GALLEGO}

RESUMEN

La recuperación de monumentos mediante la asignación de nuevos usos distintos a los originales es una práctica cada vez más frecuente en la gestión del patrimonio arquitectónico. También es cada vez mayor el número de establecimientos hoteleros localizados en edificios de gran valor histórico y/o artístico.

El origen de esta actividad se remonta a principios del siglo XX con el nacimiento de una conciencia sobre la importancia que poseía el patrimonio para la floreciente industria turística. La creación estatal de una red variada de alojamientos dio lugar a un tipo de hotel que se instalaría en edificaciones ruinosas que una vez rehabilitadas recuperarían su utilidad, logrando así armonizar la salvaguarda del patrimonio monumental español con el impulso del turismo. Esta práctica se extendió rápidamente por todo el país, y también por Galicia.

Este trabajo viene a completar una parte importante del estudio sobre el impacto del turismo y la gestión cultural en la conservación del patrimonio histórico-artístico gallego: mediante el análisis de cinco monumentos religiosos rehabilitados como establecimientos hoteleros comprobaremos cómo el abandono del inmueble supone el inicio de su inevitable ruina, demostrándose que la opción de un nuevo uso se presenta como la mejor garantía para su supervivencia, entendiendo este acto desde la capacidad del monumento de estar vivo y de participar en la sociedad del momento.

Palabras clave: patrimonio; rehabilitación; Santo Estevo de Ribas de Sil; Santa María de Aciveiro; San Clodio de Leiro; San Vicente do Pino; San Francisco de Valdedeus.

\section{RESUMO}

\section{A REUTILIZACIÓN HOTELEIRA DO PATRIMONIO MONÁSTICO GALEGO}

A recuperación de monumentos mediante a asignación de novos usos distintos aos orixinais é unha práctica cada vez máis frecuente na xestión do patrimonio arquitectónico. Tamén é cada vez maior o número de establecementos hoteleiros localizados en edificios de gran valor histórico e/ou artístico.

A orixe desta actividade remóntase a principios do século XX co nacemento dunha conciencia sobre a importancia que posuía o patrimonio para a florecente industria turística. A creación estatal dunha rede variada de aloxamentos deu lugar a un tipo de hotel que se instalaría en edificacións ruinosas que unha vez rehabilitadas recuperarían a súa utilidade, logrando así harmonizar a salvagarda do patrimonio monumental español co pulo do turismo. Esta práctica estendeuse rapidamente por todo o país, e tamén por Galicia. Este traballo ven completar unha parte importante do estudo sobre o impacto do turismo e a xestión cultural na conservación do patrimonio histórico-artístico galego: mediante a análise de cinco monumentos relixiosos rehabilitados como establecementos hostaleiros comprobaremos como o abandono do inmoble supón o inicio da súa inevitable ruína, demostrándose que a opción dun novo uso preséntase como a mellor garantía para a súa supervivencia, entendendo este acto desde a capacidade do monumento de estar vivo e de participar na sociedade do momento.

Palabras clave: patrimonio; rehabilitación; Santo Estevo de Ribas de Sil; Santa María de Aciveiro; San Clodio de Leiro; San Vicente do Pino; San Francisco de Valdedeus.

\section{TRANSFORMING THE MONASTIC HERITAGE OF GALICIA INTO HOTELS}

\section{ABSTRACT}

The recovery of monuments by means of the allocation of new distinct uses to the original ones is an increasingly frequent practice in the management of architectural heritage. And the number of hotel establishments located in buildings of great historical and/or artistic value is ever growing.

The origin of this activity goes back to the beginning of the 20th century with the birth of a consciousness about the importance heritage possessed for the flourishing tourist industry. The creation of a varied state network of accommodations originated a new kind of hotel that it would be installed in run-down buildings which, once restored would regain their utility, achieving to harmonise the protection of the Spanish monumental heritage with the impulse of tourism. This practice quickly spread throughout the whole country, and also throughout Galicia.

This research is completing an important part of the study about the impact of tourism and the cultural management in the conservation of the historical-artistic heritage in Galicia: through the analysis of five religious monuments rehabilitated as hotels we'll see how the abandonment of the real estate supposes the start of its unavoidable ruin, showing that the option of a new use presents itself as the best guarantee for its survival, understanding this act from the perspective of the capacity of the monument to be alive and to participate in the society of the moment.

KEY words: heritage; reuse; Santo Estevo de Ribas de Sil; Santa María de Aciveiro; San Clodio de Leiro; San Vicente do Pino; San Francisco de Valdedeus. 
a recuperación de edificios históricos mediante la asignación de nuevos usos distintos a los originales es una práctica cada vez más común en la gestión del patrimonio arquitectónico. También es cada vez mayor el número de hoteles localizados en edificios de gran valor histórico y/o artístico, tratándose - en algunos casos- de inmuebles abandonados o cerrados al público que vuelven a abrir sus puertas convertidos en hoteles.

La situación que presentan actualmente este tipo de establecimientos hoteleros ha ido en aumento en diversos países europeos, tal y como pone de manifiesto la relativamente reciente creación de distintas asociaciones que reúnen hoteles de toda Europa localizados en edificios con un relevante valor histórico-artístico.

La denominada European Federation of Traditional Accommodation and Historic Houses congrega diversas agrupaciones hoteleras para llevar a cabo una promoción conjunta. Dentro de esta organización predominan asociaciones que comprenden una serie de hoteles y restaurantes en edificios históricos de un mismo país, como es el caso italiano de Abitare la Storia o Châteaux \& Hôtels de France, así como otras de Irlanda, Reino Unido, Suecia, Dinamarca, Austria, Portugal y España. Esta circunstancia permite entrever la proliferación de hoteles en edificios históricos surgidos de la iniciativa individual que, a través de estas asociaciones, amplían las posibilidades de difusión de sus establecimientos. Pero esta federación también incluye cadenas hoteleras, como es el caso de Pousadas de Portugal.

La presencia española en esta federación viene de la mano de Estancias de España, surgida en 1991 como una agrupación de hoteles cuyo denominador común era su ubicación en edificios erigidos con una función diferente a la hotelera y que reunían unas condiciones de calidad y servicio determinadas; y también de Hosterías-Hospederías Reales, que agrupa a aquellos establecimientos que presentaban diversas propuestas de turismo cultural. Existen además otras agrupaciones entre las que se puede citar Hoteles con Encanto, que también reúne varios inmuebles históricos. Pero asimismo hay cadenas hoteleras multinacionales que adquirieron, de manera puntual, algún edificio histórico en España; tal es el 
caso de Occidental Hotels \& Resort-recientemente adquirida por Barceló Hotels Group- o NH Hoteles.

Por otro lado, el panorama español de este tipo de establecimientos hoteleros presenta la singularidad que supone la existencia de Paradores de Turismo de España, que paradójicamente no pertenece a ninguna de las asociaciones anteriormente citadas.

\section{NueVos USOS PARA ANTIGUOS EDIFICIOS}

El hombre siempre ha realizado construcciones para muy diversos fines y usos, adaptando su morfología y características tipológicas a determinadas necesidades, adecuando la estructura y la forma a la función que debían cumplir. También ha sido una constante la reutilización de esas edificaciones y de sus materiales en épocas posteriores para usos diferentes, provocando destrucciones y modificaciones importantes que, en ocasiones, añadían nuevos elementos transformando el inmueble original en otra construcción híbrida.

Después de la Segunda Guerra Mundial se produjo un intenso debate en toda Europa sobre la necesidad de reutilizar los edificios históricos para garantizar su supervivencia, aunque muchas veces dichas intervenciones habían comportado graves pérdidas en los monumentos. Prevalecía la doctrina de la reutilización del pasado arquitectónico dando entrada al discurso funcional para garantizar el uso de los edificios antiguos; y como hecho general se admitía que cualquier inmueble histórico era un contenedor potencial de funciones modernas. Por todo el continente europeo monasterios, hospitales, palacios y toda clase de edificios civiles se convertían en nuevos centros administrativos, museos, etc... tras ser vaciados, conservando únicamente sus fachadas y provocando una grave ausencia de relación entre la forma y la función.

El debate se perfiló en los años ochenta, cuando estas operaciones revistieron verdaderos laboratorios de ensayo para salvar multitud de edificios obsoletos. Entonces intelectuales, arquitectos e historiadores defendieron este tipo de actuaciones ${ }^{1}$, pero en la actualidad se tiene clara consciencia de que se provocaron fuertes alteraciones que no preservaron la autenticidad arquitectónica de los edificios, perdiéndose características y valores irrecuperables.

En España, en las últimas décadas, la intervención monumental se fundamentó -conceptual y económicamente- en la reutilización de los inmuebles. Durante el traspaso de competencias del Estado a las Autonomías se desató una fiebre intervencionista y rehabilitadora que tuvo dos consecuencias fundamentales: la crisis económica que revalorizaría el viejo parque edificado incrementando así su

\footnotetext{
1 Javier Rivera Blanco, De varia restauratione, Madrid, Abada, 2008, págs. 150-188.
} 
valor de uso, y la cantidad de monumentos infrautilizados y de déficits de equipamientos heredados de la dictadura, que sugirió a las nuevas administraciones democráticas el volver los ojos hacia ese patrimonio para tratar de solventar estas dos cuestiones a la vez ${ }^{2}$.

Los problemas derivados de una reutilización excesivamente intensa o inconveniente se fueron agravando en los últimos años, hasta el punto de que la rehabilitación monumental llegó a ser uno de los principales problemas con los que se encontraría el ejercicio arquitectónico europeo. Incluso el ICOMOS se vio obligado a proponer como motivo central de sus campañas la reivindicación de un uso sensato de los monumentos: un uso que permitiese compatibilizar la conservación del monumento - en el sentido de continuidad de existir- con la permanencia de sus valores esenciales ${ }^{3}$.

A finales del siglo XX, la restauración integral recomendaba usar los edificios históricos exclusivamente cuando existiera compatibilidad entre su función original y la función demandada. Se debía evitar a toda costa cualquier distorsión, dado que tanto el precio histórico pagado como el rendimiento conseguido no equilibrarían ni por asomo las ventajas esperadas ${ }^{4}$. Bien es sabido que unas formas -entendidas como tipologías- se adaptan mejor que otras a los nuevos usos, siendo estas adaptaciones más o menos difíciles de afrontar según la compatibilidad del nuevo uso con el original. (Tabla 1)

Los desajustes provenientes de la capacidad inicial en relación con los futuros usos previsibles, las contradicciones funcionales y distributivas, la ausencia de servicios e instalaciones puestas al día, etc... son algunos de los problemas que se debieron y deben superar -con mayor o menor éxito- en este tipo de intervenciones en función de la relación que se establecerá entre el nuevo uso y la tipología preexistente.

Por otra parte, la justificación de estos cambios de uso responde a una necesidad concreta que se traduce en función del objetivo perseguido por la intervención: según prime el monumento como documento, la comunidad de usuarios o el monumento como recurso, estaremos ante un cambio de uso requerido por una necesidad cultural, social o económica ${ }^{5}$.

\footnotetext{
2 Javier Rivera Blanco, "El debate sobre la pertinencia de los nuevos usos en la reciente historia de la restauración", en VIII Cursos Monográficos sobre el Patrimonio Histórico, Reinosa, Universidad de Cantabria, 1997, págs. 263-277.

3 Antonio GonzÁlez Moreno-NAVArro, "De la reutilización indiscriminada al uso sensato de los monumentos", en VIII Cursos Monográficos sobre el Patrimonio Histórico, Reinosa, Universidad de Cantabria, 1997, págs. 281-299.

4 J. Rivera Blanco, "El debate sobre...”, págs. 263-277.

5 Alberta LoRenzo AsPres, Intervencións no patrimonio galego para a industria hostaleira, A Coruña, Universidade da Coruña, 2014, págs. 121-128.
} 


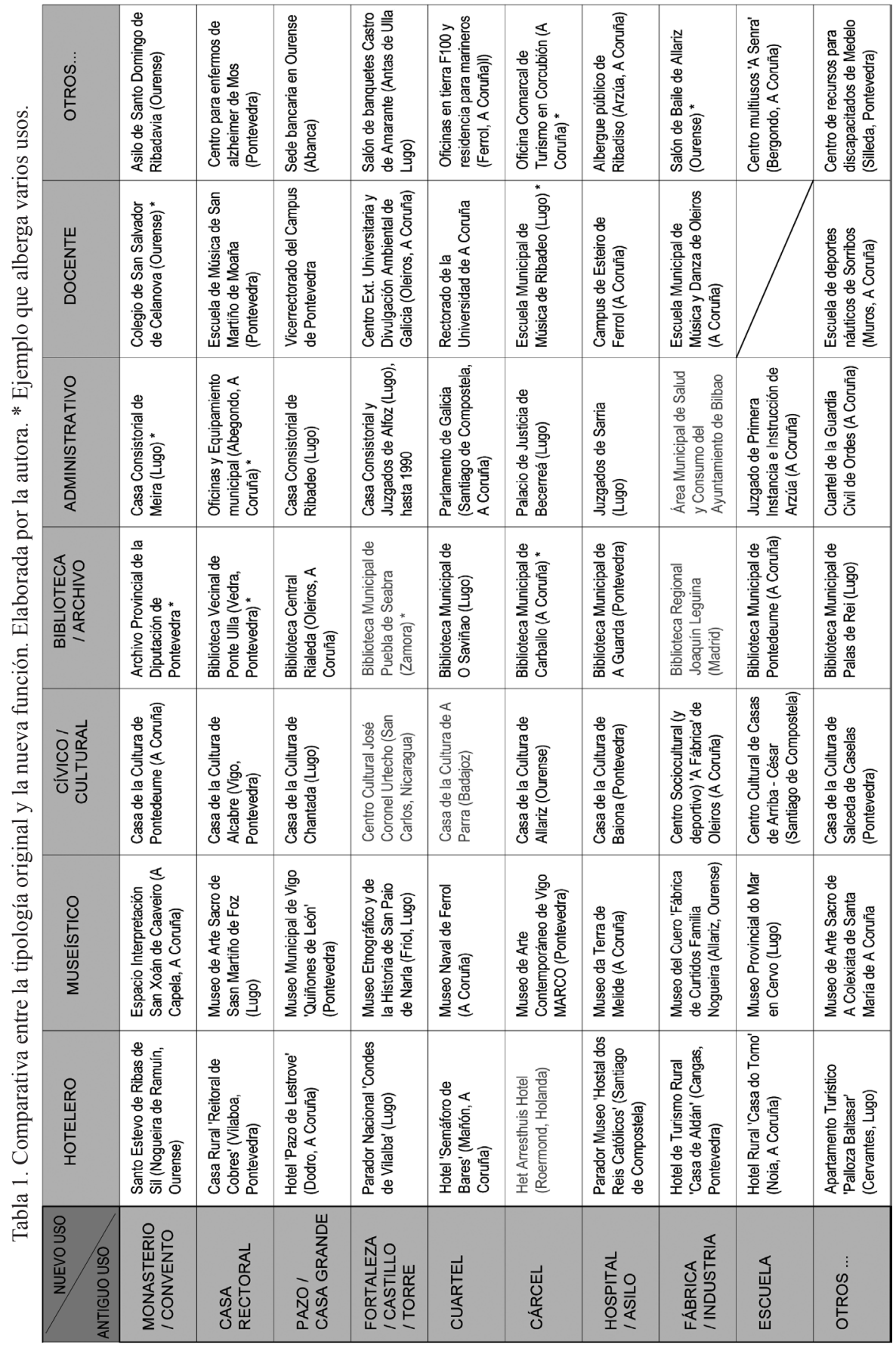


En primer lugar, la reutilización hecha por una necesidad cultural responde a una recuperación física y puesta en uso de un edificio singular para evitar su desaparición: se enfatizan los valores arquitectónicos y patrimoniales del bien para preservarlos y potenciarlos a través de una actuación de mínimos que garantice su conservación y continuidad. Por lo tanto, el nuevo uso será un uso de salvaguarda en el que el monumento es entendido como un objeto de estudio donde se actúa por el simple hecho de resultar útil para la sociedad y para la ciencia como testimonio de una parte del pasado.

Para la obtención de estos fines el nuevo uso más aplicado -partiendo de la imposibilidad de recuperación de la función original- es el de contemplativo o museístico, en el que el bien se exhibe a sí mismo.

En segundo lugar, en una rehabilitación realizada por una necesidad social, el edificio es liberado del peso que supone en su gestión el carácter histórico y documental, pasando a un concepto moderno en el que el monumento es un bien activo que tiene intencionalidad de servir como factor de desarrollo a la comunidad. Así, dicho monumento se sacrifica por la sociedad para dar respuesta a una demanda de la misma ${ }^{6}$. Y en base a esa demanda se acomete la transformación total del bien, convirtiéndolo en una mera fachada: conservada, o por cuestiones de imagen, o simplemente por las exigencias dictadas por la normativa urbanística. En este tipo de actuaciones fachadistas se suelen eliminar tanto la distribución espacial-determinada por una tipología concreta-como los elementos iconográficos del edificio, borrando así numerosas huellas históricas.

En tercer y último lugar, en una rehabilitación que responde a una necesidad económica lo que menos importa es el monumento. Presentado éste como un reclamo, el objetivo del nuevo uso -entendido como negocio- es conseguir la mayor rentabilidad. Pero el negocio dentro de un monumento histórico aparece como una oferta condicionada por las características específicas del monumento: los intereses culturales chocan de modo inevitable con las exigencias de un negocio rentable. En consecuencia, las modificaciones realizadas en el inmueble procuran una mayor funcionalidad del nuevo programa para obtener así los mayores beneficios, sin importar, una vez más, el sacrificio al que resulte sometido el bien histórico.

Un ejemplo de esta categoría es el uso hotelero, en el que se busca el mayor número posible de habitaciones con el fin de conseguir la mayor cantidad de ingresos. Un caso paradójico sería la Red Nacional de Paradores de Turismo, dado que en sus inicios intervenía en monumentos, entre otros objetivos, con la intención de salvaguardar el patrimonio del país.

\footnotetext{
6 Este sacrificio ha sido una práctica muy común en los años ochenta cuando las nuevas administraciones se encontraron con un rico - pero deteriorado- patrimonio arquitectónico disponible para albergar las dependencias e instalaciones de las recién creadas instituciones democráticas.
} 


\section{LA INDUSTRIA HOTELERA COMO NUEVO DESTINO: LA EXPERIENCIA ESPAÑOLA}

A finales del siglo XIX, junto con el visitante erudito, viajaría a España otro tipo de viajero numéricamente más cuantioso y suficientemente dotado de recursos que daría origen al fenómeno del turismo masivo organizado, cuya presencia acarrearía numerosas consecuencias para el país receptor. De esta forma, el turismo se convirtió en un medio en el que los visitantes eran vistos como un elemento revitalizador de las economías locales.

En el otoño de 1905 se presentó el gobierno liberal presidido por Montero Ríos, y desde la cartera de Fomento se anunciaron diversas reformas y la reorganización de los servicios técnicos de agricultura, industria y comercio. Para llevar a cabo este cometido se crearon distintas comisiones y se dictaron disposiciones, en las que se empleaba la riqueza y la variedad del patrimonio artístico y monumental -sobre todo urbano- como reclamo para que los nuevos turistas visitaran las ciudades y las grandes poblaciones del país ${ }^{7}$. Nacía así una clara consciencia acerca de la importancia que poseía el patrimonio para la floreciente industria turística ${ }^{8}$.

Hasta el Real Decreto del 19 de junio de 1911 no surgió un organismo que coordinase desde el propio Estado todas aquellas asociaciones y entidades oficiales que por sus competencias tenían que intervenir en temas turísticos. Nacía así la Comisaría Regia de Turismo y Cultura Artística y Popular, con Benigno de la Vega Inclán y Flaquer -II Marqués de la Vega Inclán-al frente. Desde la misma se diseñó un sistema de trabajo coherente y compacto en su totalidad y en cada una de sus partes, partiendo de un profundo conocimiento de la realidad española $\mathrm{y}$, por lo tanto, de las carencias y posibilidades que ofrecían los recursos naturales y artísticos del país. Los principales ejes sobre los que descansaba tanto la concepción teórica de la gestión turística como su aplicación práctica eran cuatro: la publicidad de España; la revalorización de la idiosincrasia española; la mejora de la red viaria; y la creación de una red variada de alojamientos ${ }^{9}$.

En este último campo de actuación, ante la insuficiente dotación de equipamientos hoteleros, se trabajó para arbitrar los mecanismos financieros, políticos y técnicos que permitiesen crear una red lo más diversa y compleja posible. Una de las singularidades metodológicas que se aplicaría en este terreno fue la fijación de una variada tipología de establecimientos, ideada teniendo en cuenta las particularidades geográficas. Y aunque variaban al tratar de satisfacer las

\footnotetext{
7 Fernando BAYÓN MARINÉ (dir.), 50 años del turismo español. Un análisis histórico y estructural, Madrid, Centro de Estudios Ramón Areces, 1999, págs. 25-45.

8 Luis FERnÁNDEZ Fuster, Introducción a la teoría y técnica del turismo, Madrid, Alianza Editorial, 1989, págs. 815-834.

9 María Luisa Menéndez Robles, El Marqués de la Vega Inclán y los orígenes del turismo en España, Madrid, Secretaría General de Turismo, 2006, págs. 172-189.
} 
necesidades de los diferentes tipos de público, poseían unidad en cuanto al confort y a los diseños decorativos.

La primera de estas tipologías -el hotel de lujo- escaseaba en las grandes ciudades del país: el primero de estas características se levantó en 1905 en la colina de la Alhambra de la mano del conde de Benalúa. Pero cuando Alfonso XIII ascendió al trono, trató de convertir Madrid en una capital europea, para lo que era necesario dotar a la ciudad de este tipo de establecimientos. El primero en construirse fue el Ritz -en 1908-, obra del arquitecto francés Charles Mewes; tras él se erigió el hotel Palace, bajo la dirección conjunta de Ferrés Puig y Eduard Niermans ${ }^{10}$.

Bien distinta era la situación de la infraestructura hotelera en el resto de las capitales españolas, donde tan sólo unas pocas ciudades como San Sebastián contaban con establecimientos de calidad. En el resto de las provincias apenas había hoteles confortables, y con el fin de dotar de una infraestructura hotelera más modesta a todo tipo de localidades, nacieron las hospederías y las residencias. Las primeras -definidas como establecimientos regionales- permitirían recibir en condiciones idóneas a un turismo especialmente interesado por los parajes ubicados fuera de los circuitos habituales; las segundas nacieron con el objetivo de dotar de hoteles especializados a artistas e investigadores, donde la biblioteca y los salones de reunión gozaban de gran importancia y se convertían en el centro neurálgico del establecimiento. También se trató de impulsar otro tipo de alojamientos de carácter especializado: dado que la hidrología médica atraía a numerosos visitantes, era necesario fijar sus características y variantes en función del tipo de enfermedad. Otro modelo en el sistema de alojamientos promovidos fueron las casas rurales ${ }^{11}$.

Sin embargo, la creación más afortunada fue un tipo de hotel de carretera adaptado a los estilos regionales y a las necesidades de cada localidad al que se denominó parador, y que desde sus orígenes disfrutaría de una gran aceptación.

Con la idea de ser instalados en edificaciones ruinosas que una vez rehabilitadas recuperarían su utilidad, estos hoteles de carretera lograban armonizar la salvaguarda del patrimonio monumental con el impulso del turismo y el acceso a los parajes naturales localizados por todo el país. Se pretendía garantizar además con el nuevo uso la supervivencia del monumento, algo habitual en nuestros días pero infrecuente y llamativo entonces, cuando la sensibilidad hacia la conservación del patrimonio no estaba tan generalizada ni amparada por la legislación.

\footnotetext{
${ }^{10}$ Carmelo Pellejero Martínez, "La promoción del turismo en España durante la primera mitad del siglo XX: el papel del Estado”, Información Comercial Española, 730 (1994), págs. 127-136.

${ }^{11}$ M. ${ }^{\mathrm{a}}$ L. MenÉndez Robles, El Marqués de la Vega Inclán ..., págs. 172-202.
} 
La idea de levantar el que habría sido el primer parador estaba ya muy clara en 1911: el Marqués de la Vega Inclán había escogido como emplazamiento la sierra cordobesa, en cuyo entorno se levantaba la ciudad de Medina Azahara y en la que había localizado las ruinas de un antiguo monasterio jerónimo abandonado tras la desamortización.

En esa maravillosa sierra de Córdoba, en el sitio más delicioso y bien orientado se esconde un monumento de finales del XV en ruinas pero con claustro, salones, fachadas, etc... que antes que se destruya quiero sostenerlo, conservarlo y hacer la más exquisita residencia que a lo mejor exista conservando las ruinas y construyendo en el interior departamentos con terrazas al más maravilloso jardín del mundo con la austeridad en mobiliario y ornamentación de benedictino pero con inmenso confort. El sitio lo escogieron los califas, y lo consagraron los frailes Jerónimos ${ }^{12}$.

De la Vega Inclán confiaba en las grandes posibilidades que ofrecía el antiguo monasterio para - una vez reconstruido y reedificado- dotarlo interiormente del mayor confort y de una austeridad ornamental que serían el marchamo de la casa. Finalmente, el proyecto no prosperó por motivos económicos.

Tras la primera cacería de Alfonso XIII en el coto real de Gredos en 1911, éste quedó tan entusiasmado con los parajes que trasladó al comisario regio la conveniencia de fomentar en ellos el turismo. Así se inició un proceso que desembocaría en la construcción del Parador Nacional de Gredos bajo la dirección del arquitecto Julián Delgado Úbeda ${ }^{13}$. Inaugurado este primer establecimiento en octubre de 1928, se constituyó la Junta de Paradores y Hosterías del Reino. Al mismo tiempo, también se iniciaron las obras para el parador de Mérida: esta vez el Estado no escatimó en gastos.

Mediante la Real Orden del 12 de junio de 1928 se autorizaba el comienzo de las obras en el antiguo Convento-Hospital de los Ermitaños de Jesús o de los Hospitalarios, atendido por los franciscanos mendigos de esa orden, pero que era propiedad municipal habiendo instalado en él la cárcel de partido y el juzgado ${ }^{14}$.

\footnotetext{
${ }_{12}$ M. ${ }^{\mathrm{a}}$ L. Menéndez Robles, El Marqués de la Vega Inclán..., págs. 203-205.

13 El arquitecto, atendiendo a las instrucciones del comisario regio, proyectó un edificio de aspecto sólido y sobriedad formal casi conventual. Una de las escasas concesiones ornamentales del conjunto es la colocación de dos portadas de los siglos XV y XVI procedentes del derribo de edificios de la localidad vecina de Villacastín. Véase Luis LaVAur, “Turismo de entreguerras (1919-1939)”, Estudios Turísticos, 68 (1980), págs. 3-36.

${ }^{14}$ En 1725 se inició la construcción de este pequeño edificio dedicado a Hospital, asentado sobre los restos romanos del foro emeritense y de una iglesia visigoda totalmente arrasada y se hizo según los cánones del
} 
Poco después de iniciada la intervención se decretó el relevo de la Comisaría Regia de Turismo por el Patronato Nacional de Turismo. Su titular quedaría relevado de todas las competencias turísticas excepto de las relativas al parador de Mérida por orden expresa de Primo de Rivera. Tan sólo disponía de un año para poner el establecimiento en marcha, pero no lo logró: la inauguración tuvo lugar en el verano de 1933.

Mérida supuso el inicio de una nueva práctica que haría gran fortuna con la expansión de la red de paradores, consistente en situar estos establecimientos en edificios antiguos; y su ejemplo no tardaría en ser imitado. El alcalde de Ciudad Rodrigo (Salamanca) se presentaría ante el general Primo de Rivera para solicitar la creación de un establecimiento de estas características en su villa. Igual idea tuvo el regidor de Úbeda, que cedió al Patronato Nacional de Turismo el palacio renacentista del Marqués de Donadío para instalar un parador o hostería a la antigua usanza, destinada a los turistas que visiten la villa ${ }^{15}$. El parador sería inaugurado en el 1930, en el mismo año que el de Oropesa, cuyo alcalde ofreció el castillo de la localidad, residencia habitual de los condes Álvarez de Toledo ${ }^{16}$.

En general, los castillos, conventos o residencias nobiliarias en los que se emplazaron este tipo de establecimientos hoteleros sufrieron transformaciones perturbadoras por parte de los arquitectos oficiales encargados de su acondicionamiento. Propusieron escenografías folcloristas y pintorescas, prescindiendo de la realidad histórica o del valor documental del monumento en un momento en el que la calidad técnica y el rigor de la actividad proyectiva sobre la arquitectura histórica eran ínfimos ${ }^{17}$. Coincidió que usualmente estas obras fueron hechas al margen de la Dirección General de Bellas Artes: no existieron ni memorias ni planos ni investigación de cada edificio en el que se iba a intervenir, optándose por diseños historicistas como solución estética, para obtener una apariencia atractiva dirigida

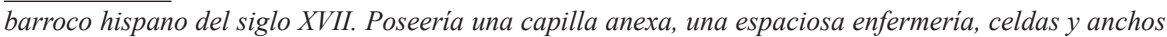
corredores, dispuestos en torno a un amplio patio central de planta cuadrada, donde se reaprovechan restos constructivos romanos y visigodos. En la huerta conventual los monjes instalaron un famoso Jardín de Antigüedades formado con los restos de las remociones del entorno. (...) En la fachada se conservó un escudo con armas reales, en alusión al patronato regio con el que fue distinguido este Hospital. Fue abandonado por los monjes durante las guerras napoleónicas no regresando hasta 1816, para ocuparse desde aquella y hasta 1837, en la reparación de los cuantiosos daños sufridos en el edificio, que desalojaron definitivamente dos años más tarde, como consecuencia de la Desamortización. Los sucesivos usos que recibió como manicomio entre 1842 y 1851 y como cárcel de partido después, no harían más que agravar su deterioro.

15 Juan Eslava Galán y Francisco Ontañón, Paradores históricos, Barcelona, Lunwerg Eds, 1997, págs.138-143.

16 Antonio Ulled Merino, La recuperación de edificios históricos para usos turísticos. La experiencia española, Madrid, Tecniberia, 1986, págs. 45-69.

17 Alfonso Muñoz Cosme, La conservación del patrimonio arquitectónico español, Madrid, Instituto de Conservación y Restauración de Bienes Culturales, Madrid, 1989, págs. 161-168.
} 
al turismo. Este fue el objetivo que prevaleció sobre la sinceridad y honestidad en el tratamiento de inmuebles que eran monumentos histórico-artísticos. Dicha propuesta enlazaba con el renacer tras la Guerra Civil de las ideas de la escuela restauradora de comienzos de siglo: fue así como acabó imponiéndose durante los años de eclosión de los paradores el pastiche bajo la denominación de estilo parador en referencia a unas ideas estéticas y arquitectónicas que desvirtuaban el modelo.

Durante el período de postguerra se crearon paradores con diversos fines, entre otros la difusión de los escenarios más importantes de la contienda; pero se seguía manteniendo el objetivo inicial de potenciar los atractivos turísticos del país a la par que salvaguardar el patrimonio arquitectónico. Sin embargo, el mayor proceso expansivo se produjo en la década de los sesenta coincidiendo con el importante desarrollo turístico que vivió el país: en estos años, la red pasó de cuarenta a ochenta y tres establecimientos.

El primer parador gallego abrió sus puertas el 15 de enero de 1955 en Pontevedra, con veintiséis habitaciones. Bajo la dirección del arquitecto de la Dirección General de Turismo, Manuel Sainz de Vicuña y García Prieto, se llevó a cabo la rehabilitación de la conocida como Casa del Barón, un palacio renacentista del siglo XVI - antigua residencia de los Condes de Maceda- situado en pleno centro histórico ${ }^{18}$. Las obras de reutilización superaron los cuatro millones de pesetas y estuvieron acompañadas por una modificación total de las vías de acceso y del entorno ${ }^{19}$.

Apenas unos meses antes se había inaugurado el caso más mediático de rehabilitación de edificio histórico para fines hoteleros en cuanto al papel jugado como importante baza para el reclamo turístico de cara a la revitalización del sector: el actual Hostal dos Reis Católicos.

En diciembre de 1952, los arquitectos Manzano Monis, Osuna Fajardo y Valverde Viñas redactaron un proyecto de consolidación y reforma del Hospital Real de Santiago para su adaptación como Parador de Turismo y Albergue, con

\footnotetext{
18 Radio Televisión Española, Nuevo Parador Nacional 'Casa del Barón': una realización de la Dirección General de Turismo en Pontevedra, Galicia. Documento consultado en la Filmoteca Española, con la referencia NOT N 629 A. Madrid, 1955.

19 En enero de 1972 hacía entrada en el registro del Concello pontevedrés una copia del proyecto redactado por Sainz de Vicuña y García Prieto para reformar y ampliar el establecimiento: se proponía la construcción de un nuevo volumen de tres plantas, aprovechando la zona del jardín alto, de manera que no modificase el aspecto de la preexistencia y la entrada principal. Las nuevas obras fueron inauguradas dos años más tarde, dando lugar a la imagen actual del parador. Manuel Sainz de Vicuña y García Prieto, Proyecto de reforma y ampliación del Parador de Turismo Casa del Barón, Pontevedra. Documento consultado en el Archivo Municipal de Pontevedra, con la referencia 735-172/C804-13. Madrid, 1972.
} 
el objetivo de albergar a la gran masa de peregrinos que llegaban diariamente a Compostela y remediar las deficiencias de hospedaje existentes en la ciudad.

Considerando intocable la fachada del Obradoiro, la nueva ordenación del inmueble respondía a una jerarquización del espacio condicionada por la visita a Compostela del Jefe de Estado con motivo de los actos de celebración del Año Santo de $1954^{20}$. Se proyectaron tres zonas fundamentales y con acceso independiente: una con las habitaciones propias para el alojamiento del Jefe del Estado y su séquito, situada en la parte noble del antiguo hospital; otra zona destinada a parador de turismo, con más de cien plazas ofertadas; y por último un albergue de peregrinos de condición modesta, que ocupaba la parte posterior del edificio ${ }^{21}$. Esta nueva división trajo consigo reformas en todas las plantas, y tras el desalojo del edificio, las obras comenzaron en agosto de 1953. Se pretendía seguir la premisa de no efectuar ninguna adaptación o interpretación de estilos antiguos, aunque ello no impidió la convivencia de artesonados originales con las vigas de hormigón, mientras que los muebles fueron reemplazados por reproducciones de piezas antiguas mezcladas con otras modernas. Estas intervenciones tan profundas, aparentemente respetuosas, fueron juzgadas de manera crítica ${ }^{22}$.

Cabe destacar que, a pesar de su declaración como Monumento Nacional en 1931, la entrada al conjunto estuvo prohibida para la mayoría de los vecinos de Santiago hasta mediados de los años sesenta, estando custodiado el acceso por un portero que tan sólo permitía el paso a los usuarios del establecimiento ${ }^{23}$. Posteriormente, con la apertura de una cafetería pública, los compostelanos pudieron disfrutar de las renovadas estancias del que, históricamente, había sido su hospital más representativo.

En los años ochenta se realizaron diversas intervenciones en el inmueble con la finalidad de adecuarse a las necesidades que los nuevos tiempos exigían, así como a las demandas propuestas para su inclusión en la Red Nacional de Paradores.

Durante las tres décadas que separan estas dos incorporaciones a la red, fueron inaugurados, entre otros, los establecimientos históricos de Cambados -resultado de la rehabilitación del pazo de la familia Bazán- en 1966; el de Baiona ${ }^{24}$,

\footnotetext{
20 Julio Cano Lasso, Rafael de la Joya y Fernando Moreno Barberá, "Hostal de los Reyes Católicos en Santiago de Compostela”, Revista Nacional de Arquitectura, 156 (1954), págs. 3-24.

${ }^{21}$ Julián L. Manzano Monis, José Osuna Fajardo y Jesús Valverde Viñas, Proyecto de consolidación y reforma del Hospital de Santiago de Compostela para su adaptación a Parador de Turismo y Albergue de Peregrinos, Archivo Histórico Universitario de Santiago de Compostela, legajo 1952-1971. Madrid, 1952.

22 Alberta Lorenzo Aspres, "Hospital Real de Santiago de Compostela", en Intervencións no patrimonio galego para a industria hostaleira, A Coruña, Universidade da Coruña, 2014, págs. 573-620.

${ }^{23}$ Luis Seonne López, "Una hospedería de lujo”, Galicia Emigrante, 4 (1954), pág. 1.

${ }^{24}$ El Parador Nacional de Baiona es en realidad un falso arquitectónico: en el actual inmueble sólo se conservaron el escudo y la bóveda del siglo XVI - que ahora cubre el espacio de la escalera principal de
} 
también en 1966; o el de Vilalba un año más tarde, donde la torre medieval de los Andrade fue reutilizada como el parador más pequeño de la compañía con tan sólo seis habitaciones ${ }^{25}$.

Con el cambio de siglo, la empresa comenzó a gestar la idea de un nuevo tipo de parador basándose en el hecho de que más de la mitad de sus establecimientos se situaban en edificios históricos: el Parador Museo, con el que se pretendía ofrecer un aliciente más a los clientes que se alojaban en estos edificios de la cadena, contribuir a la difusión del arte y de la historia de España, y atraer a más visitantes españoles y extranjeros ${ }^{26}$.

Finalmente, en el mes de noviembre de 2009 se inauguró el primer parador museo de la red: fue Santo Estevo de Ribas de Sil. Meses después, coincidiendo con la celebración del año jacobeo, sería el Hostal dos Reis Católicos quien luciese esta nueva denominación.

\section{GALICIA: LA REUTILIZACIÓN HOTELERA DE SU PATRIMONIO RELIGIOSO}

Dentro del amplio patrimonio monumental arquitectónico gallego, los monasterios y conventos constituyen un conjunto claramente diferenciado. De los treinta y un cenobios catalogados como Bien de Interés Cultural, sólo cinco funcionan actualmente como establecimientos hoteleros.

Ordenados por la fecha de redacción del primer proyecto, veremos la evolución en el desarrollo de las soluciones adoptadas, completando a su vez una parte importante del estudio sobre el impacto del turismo y la gestión cultural en la conservación del patrimonio histórico-artístico de Galicia.

\footnotetext{
acceso al establecimiento-, pertenecientes a la capilla mayor del convento franciscano desaparecido tras la desamortización de Mendizábal y que ocupaba un lugar próximo a donde hoy se erige el parador. Alberta Lorenzo Aspres, "Parador Nacional 'Conde de Gondomar'”, en Intervencións no patrimonio galego para a industria hostaleira, A Coruña, Universidade da Coruña, 2014, págs. 693-730.

${ }^{25}$ Así estuvo funcionando durante casi dos décadas, pero al comprobar su escasa -o nula- rentabilidad, Paradores Nacionales decidió acometer su ampliación en el año 1996. Fernández-Cuenca Gómez mantuvo la torre con las seis habitaciones, pero dejándola completamente exenta para acusar al máximo su arquitectura -restaurando y eliminando añadidos-. Con esto se conseguiría otorgar mayor importancia al monumento, que se enlazó mediante una galería acristalada al nuevo edificio: una construcción en forma de L con estilo de pazo regional. Alberta Lorenzo Aspres, "Torre-Fortaleza dos Andrade”, en Intervencións no patrimonio galego para a industria hostaleira, A Coruña, Universidade da Coruña, 2014, págs. 653-690. 26 A la hora de valorar la musealización de un parador existirían distintos argumentos: la importancia de su patrimonio arquitectónico y monumental, la importancia de su historia, la importancia de su entorno y la importancia de su proyecto de transformación como establecimiento hotelero. En "Qué es un Parador Museo", Paradores, 23 (2009), págs. 5-9.
} 


\section{Santo Estevo de Ribas de Sil (Nogueira de Ramuín, Ourense)}

Situado en el corazón de la Ribeira Sacra, el actual Parador Museo de Santo Estevo es el resultado final de una serie de acciones que, con mayor o menor fortuna, han estado siempre encaminadas a la conservación del inmueble.

Su camino hacia la ruina comenzó con el paso de las tropas francesas por Ourense en 1809, cuando se instalaron en él el tiempo suficiente para saquearlo. Las desamortizaciones supusieron el abandono de sus fábricas, por lo que fue puesto en venta en 1841. Desde un primer momento, el obispo de Ourense reclamó la iglesia como parroquial y parte del monasterio para casa rectoral; pero la ruina ya había iniciado su avance ${ }^{27}$. Hasta 1923 no se reconoció su valor patrimonial, año en el que fue declarado Monumento Nacional. Sin embargo, el deterioro se prolongaría hasta la década de los sesenta, momento en el que se realizaron las primeras obras de conservación bajo la dirección de Pons Sorolla ${ }^{28}$.

Una vez asumidas las competencias en materia de cultura por parte de la Xunta de Galicia en 1983, se abordaría una nueva etapa en la que se apostaba por la recuperación total del conjunto. En una primera actuación -realizada por Suances Pereiro, Freixedo Alemparte y Vecoña Pérez- se consolidaron las fábricas existentes y se consiguió un volumen externo continuo frente a un espacio interno literalmente vacío preparado para albergar cualquier uso posterior. En dicha intervención, tomaría especial relevancia mediática ${ }^{29}$ la solución vidriada adoptada para subsanar la ausencia del lienzo norte del Claustro Grande, del cual sólo se conservaban las basas de las columnas ${ }^{30}$.

Descartado entre otros el uso como Archivo Muerto de la Xunta, se acometieron nuevas actuaciones para dotarlo de las infraestructuras necesarias para el mero disfrute turístico y cultural, inaugurándose en los años noventa el albergue

\footnotetext{
${ }_{27}$ Entre otra bibliografía, para la historia de Santo Estevo podemos consultar: Emilio DuRo PEÑA, El monasterio de San Esteban de Ribas de Sil, Orense, Instituto de Estudios Orensanos Padre Feijoo, 1977. Emilio Duro Peña y José Platero Paz, Historia, arte y entorno del Monasterio de Ribas de Sil, Ourense, Caixa Ourense, 1990. Alberta Lorenzo Aspres, "Santo Estevo de Ribas de Sil", en Intervencións no patrimonio galego para a industria hostaleira, A Coruña, Universidade da Coruña, 2014, págs. 271-316. Rosa MéNDEZ ForTe, "El monasterio de San Esteban de Ribas de Sil", en La conservación de los monumentos arquitectónicos de Galicia (1840-1940). Ferrol, Émbora Editorial, 2010, págs. 568-581. Arturo VÁzQueZ NúÑEz, "El monasterio de Ribas de Sil", Boletín de la Comisión Provincial de Monumentos Históricos y Artísticos de Orense, 15 (1900), págs. 261-280.

${ }^{28}$ Belén M. Castro Fernández, "Nogueira de Ramuín. Monasterio de Santo Estevo de Ribas de Sil", Francisco Pons-Sorolla y Arnau, Arquitecto-Restaurador: Sus Intervenciones en Galicia (1945-1985), tesis doctoral, Santiago de Compostela, Facultad de Geografía e Historia, 2008, págs. 603-616.

${ }^{29}$ Concepción Fontenla Sanuan, "San Esteban de Ribas de Sil en el origen de la restauración actual en Galicia. Polémica y restauración, Loggia, 7 (1999), págs. 20-27.

30 Alfredo Freixedo Alemparte, Javier Suances Pereiro y Manuel Vecoña Pérez, Proyecto básico y de ejecución de obras de intervención en el monasterio de San Esteban de Ribas de Sil. Archivo de la Dirección Xeral de Patrimonio Cultural, referencia 1986/011. Incluye reformados (1988/016) y fases posteriores (1989/015). Ourense, 1986.
} 


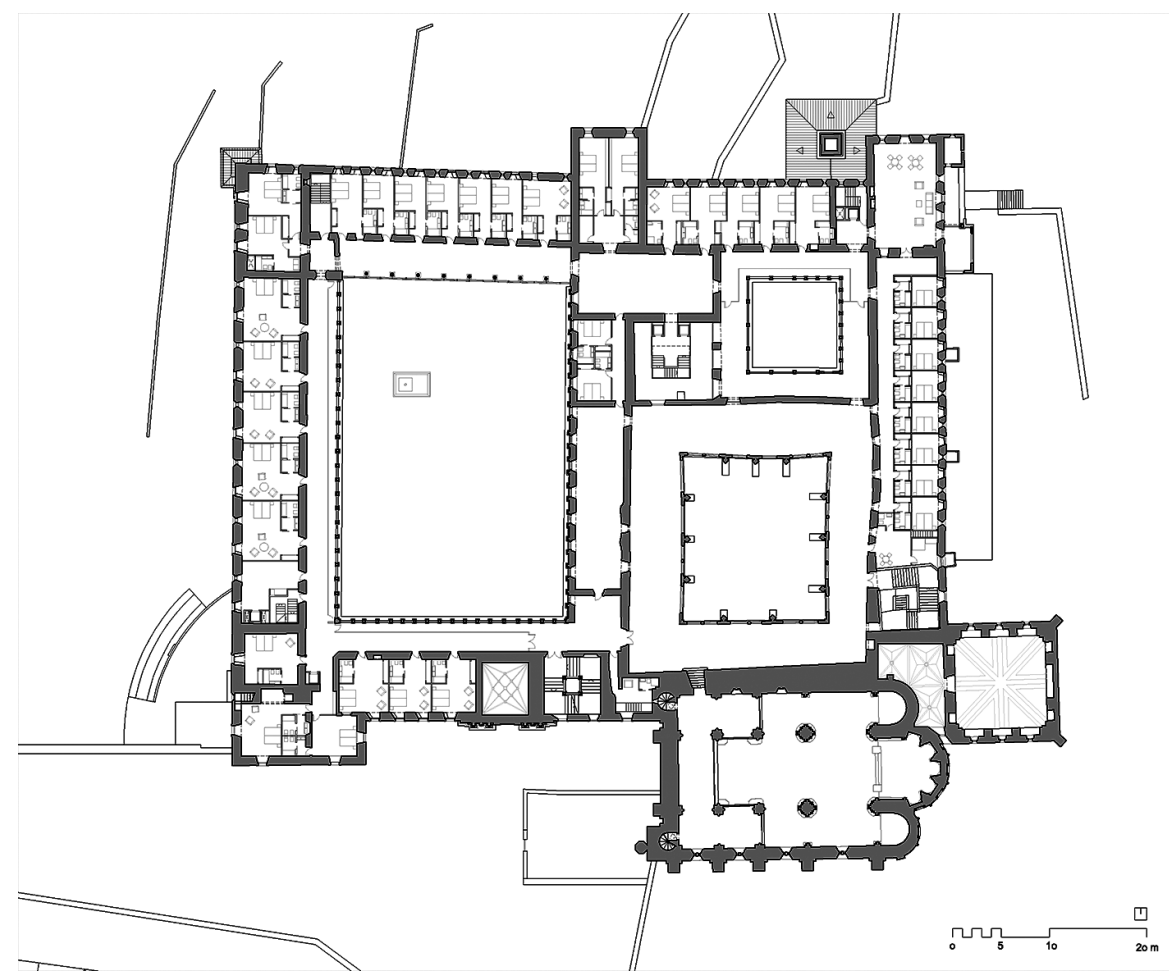

Plano 1. Planta primera de Santo Estevo de Ribas de Sil. En negro se señalan las obras realizadas para su conversión en establecimiento hotelero. (Planimetría elaborada por la autora)

O Mosteiro con un total de treinta plazas ${ }^{31}$. Finalmente, en abril de 1999 empezó la rehabilitación definitiva del conjunto para su conversión en hotel. De este proyecto se encargaron de nuevo Freixedo Alemparte y Suances Pereiro: el objetivo era compatibilizar la conservación de las estructuras arquitectónicas con el nuevo uso propuesto, manteniendo el carácter de la edificación como motor socioeconómico de la Ribeira Sacra ${ }^{32}$. (Plano 1) Y a medida que se fueron ejecutando estas obras se firmó un acuerdo con Paradores de Turismo para la explotación del nuevo establecimiento, inaugurándose oficialmente en julio de 2004.

La rehabilitación integral del conjunto se realizó mediante sobrias soluciones con el objetivo de evitar historicismos o la simple reproducción sistemática de

\footnotetext{
31 Alberta Lorenzo Aspres, "Santo Estevo de Ribas de Sil”, en Intervencións no patrimonio galego para a industria hostaleira, A Coruña, Universidade da Coruña, 2014, págs. 271-316.

32 Alfredo Freixedo Alemparte y Javier Suances Pereiro, Proyecto básico y de ejecución de rehabilitación del monasterio de San Esteban de Ribas de Sil para uso hotelero, Archivo de la Dirección Xeral de Patrimonio Cultural, referencia 1999/216. Incluye fase posterior (2000/015). Ourense, 2000.
} 

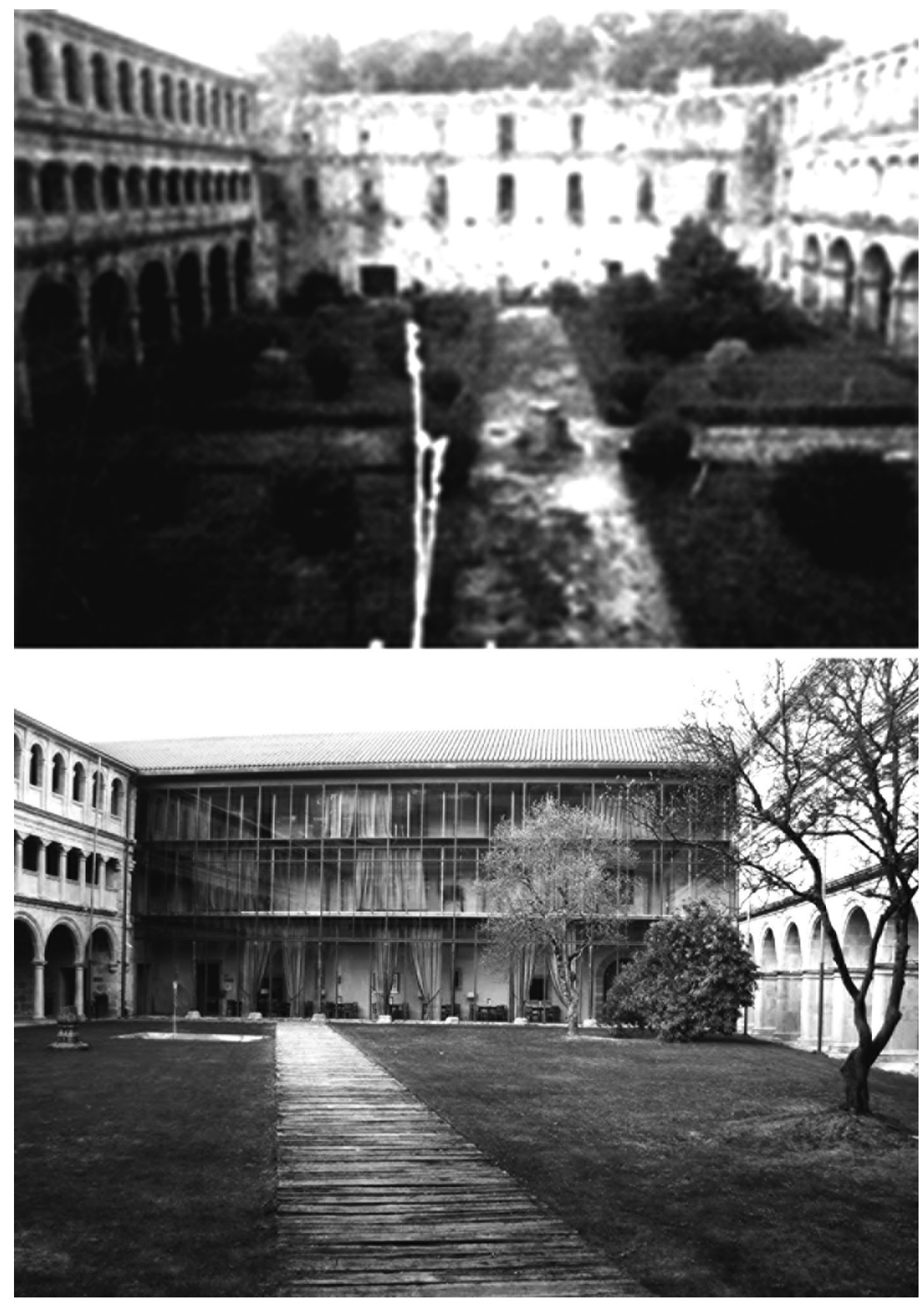

Fig. 1. Vista del ala norte del claustro grande: 'inexistente' en 1909 (AMB Meakin) y reconstruida mediante la solución de un muro cortina, 2014. (Archivo fotográfico de la autora) 
elementos antiguos ${ }^{33}$. Sin rechazar el uso de materiales actuales o de innovaciones constructivas -que se muestran perfectamente reconocibles-, los arquitectos intentaron siempre respetar la autenticidad e identidad del monumento. Esta intención también tuvo su reflejo en las soluciones adoptadas en el momento de definir los ambientes interiores, cargados de contrastes temporales.

En general, el criterio que más imperó fue la máxima de que toda actuación debía ser reversible. Así se demostró con la solución del muro cortina en el claustro grande: aunque la idea no disfrutó de una gran acogida en un primer momento, se trataba de una actuación que seguía fielmente unos criterios de reversibilidad además de no suponer daño alguno para el monumento. La solución final devolvió al conjunto la armonía de sus proporciones y permitió la completa lectura espacial evidenciando la distinción entre lo nuevo y lo preexistente. (Fig. 1) En cuanto al añadido ex novo del pabellón de servicios, apenas modificó la imagen del conjunto dado su reducido impacto visual.

\section{Santa María de Aciveiro (Forcarei, Pontevedra)}

Actualmente, el Hotel Monasterio de Aciveiro es el resultado de una sucesión de actuaciones cuyo objetivo principal era lograr un programa funcional que garantizase el mantenimiento y la supervivencia del conjunto monástico.

En la segunda mitad del siglo XVIII, el cenobio acogió el Colegio de Teología Moral de Vilanova de Oscos; por lo que es de suponer que el inmueble se encontraba en pleno rendimiento cuando hicieron su aparición en la comarca las tropas francesas, que saquearon, arrasaron e incendiaron el conjunto. Tras su expulsión, sobrevivieron diez religiosos que apenas lograban mantener las fábricas en pie: así hasta la desamortización, que provocó la incautación de todos los bienes del cenobio y la disolución definitiva de la comunidad ${ }^{34}$.

Con la declaración de Monumento Nacional en junio de 1931, comenzó una lucha por su supervivencia. Las obras de conservación y consolidación reclamadas por Alejandro Ferrant -arquitecto conservador de zona- fueron relativamente materializadas una década más tarde por Menéndez Pidal y Pons Sorolla. Después, las actuaciones fueron concebidas como un proceso gradual en dos etapas: la primera, centrada en el templo propiamente dicho; y la segunda, en la

\footnotetext{
33 A. Freixedo Alemparte y J. Suances Pereiro, Proyecto básico y de ejecución... Memoria descriptiva.

${ }^{34}$ Entre otra bibliografía, para la historia de Santa María de Aciveiro podemos consultar: Alberta LORENZO AsPres, "Santa María de Aciveiro", en Intervencións no patrimonio galego para a industria hostaleira. A Coruña, Universidade da Coruña, 2014, págs. 365-406. Antonio RodríguEz Fraíz, O mosteiro de Aciveiro. Terra de Montes, Pontevedra, Diputación de Pontevedra, 2005. Beatriz Vaquero Díaz, "Fontes documentais para o estudio do Mosteiro de Santa María de Acibeiro do Arquivo da Catedral de Ourense", en II Congreso Internacional sobre el Císter en Galicia y Portugal, Ourense, Xunta de Galicia, 1999, págs. 951-994.
} 


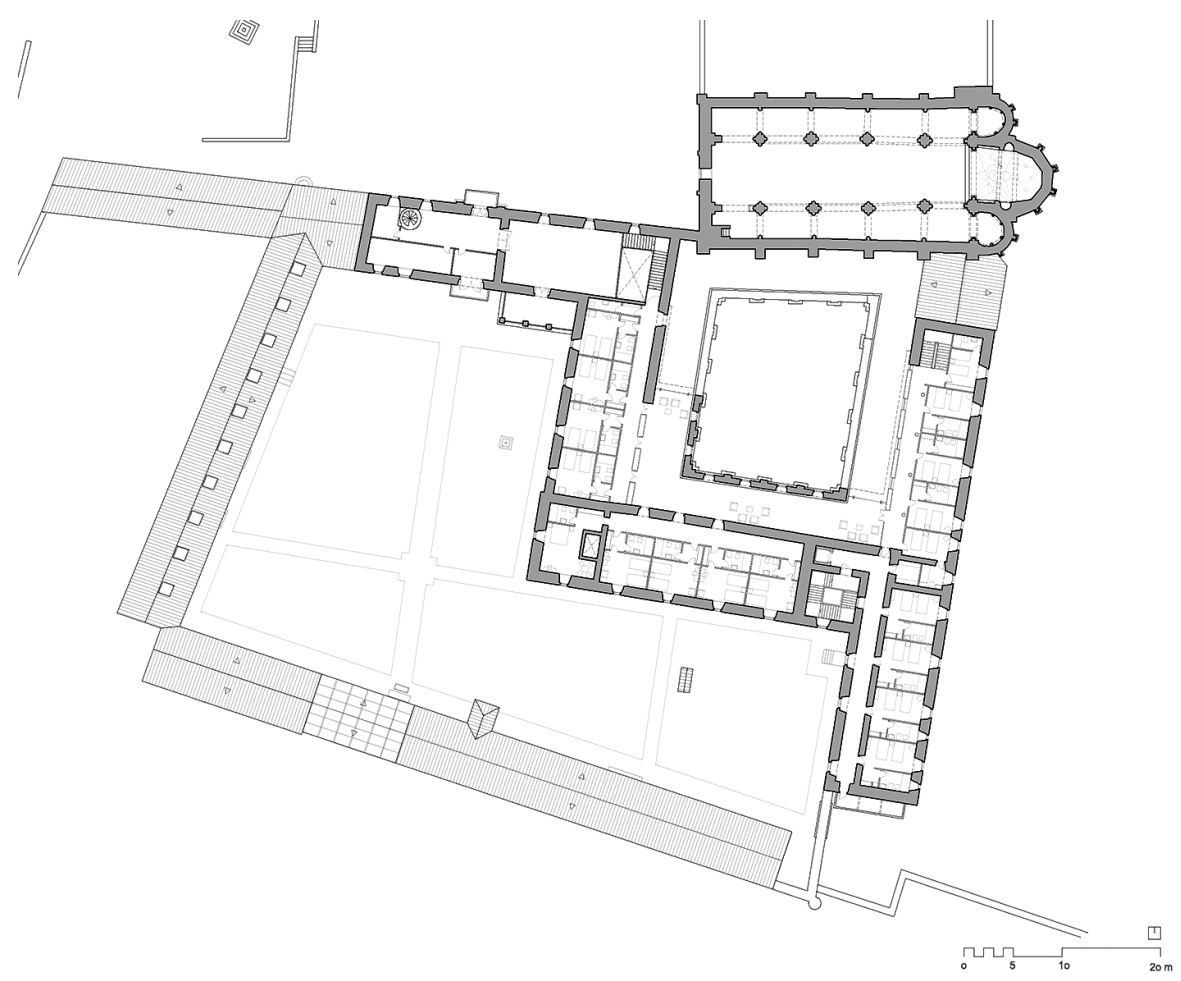

Plano 2. Planta primera de Santa María de Aciveiro. En negro se señalan las obras realizadas para su conversión en establecimiento hotelero. (Planimetría elaborada por la autora)

búsqueda de una concepción original medieval del conjunto. Las consecuencias de estas intervenciones quedaban recogidas en la redacción del Proyecto Piloto para su rehabilitación integral, ejecutado a través de una sucesión de fases en las que el destino funcional de las dependencias variaba con cada una de las etapas de actuación ${ }^{35}$.

Finalmente, en 1998 con el monumento totalmente consolidado y con un presupuesto adecuado que permitiese la posibilidad de afrontar obras de cierta envergadura, se decidió dar un uso específicamente turístico al cenobio. El nuevo alojamiento dispondría de diez cuartos dobles y de dependencias de cafetería-restaurante, cocina y almacén. Así mismo -como complemento-se preveían estancias de uso múltiple. Inaugurado con el nombre de Hospedaría de San Gonzalo das

\footnotetext{
35 Jaime Rodríguez Abilleira, Proxecto piloto para a rehabilitación integral do Mosteiro de Acibeiro. Forcarei-Terra de Montes. Archivo de la Dirección Xeral de Patrimonio Cultural, referencia 1992/163. Pontevedra, 1992.
} 

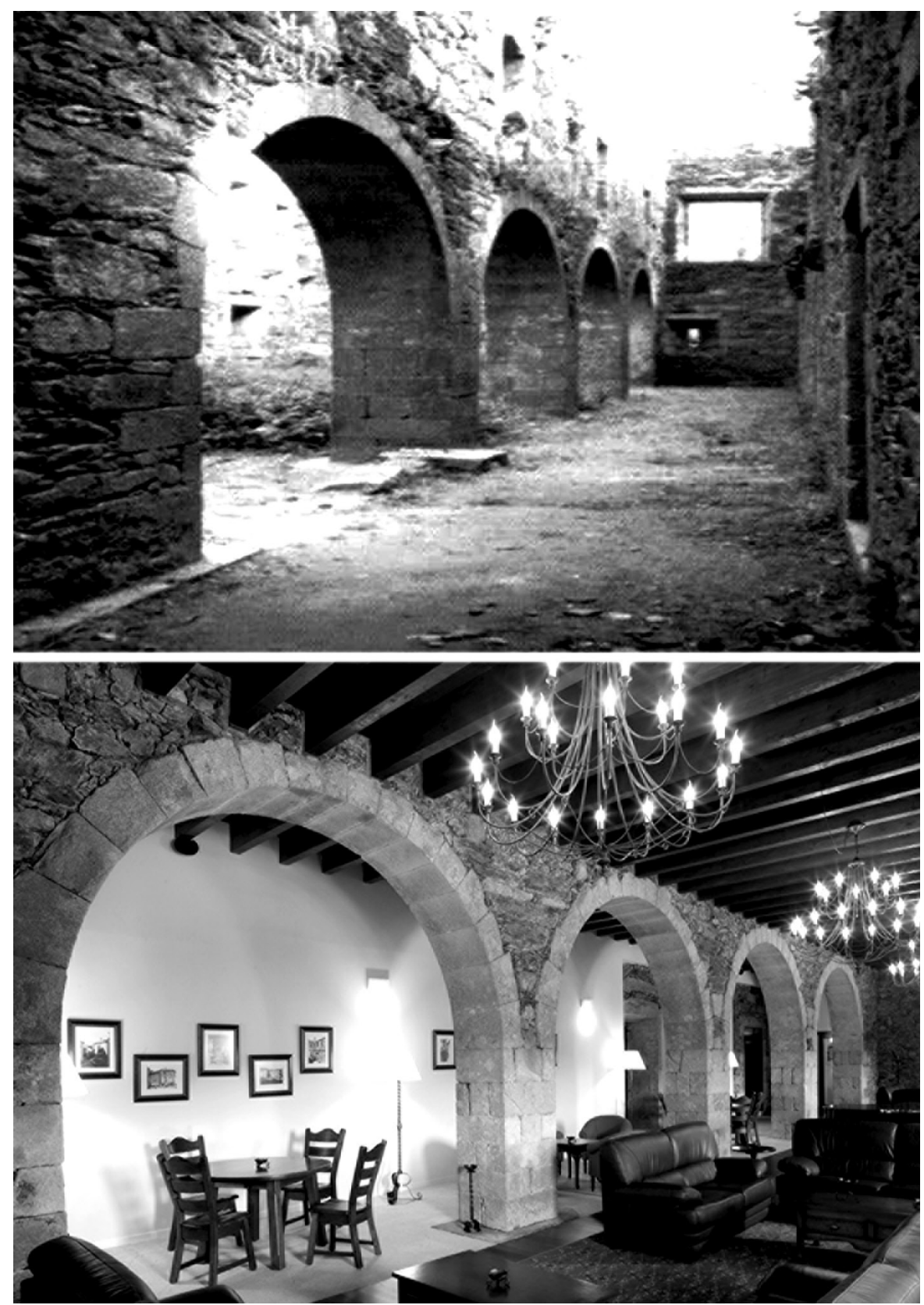

Fig. 2. Detalle de una de las estancias del antiguo monasterio de Aciveiro, en la actualidad reutilizada como salón social del hotel. (Collarte Rodríguez; Archivo fotográfico de la autora) 
Penas se mantuvo en funcionamiento durante tres años con ciertas anomalías, agravadas por la capacidad limitada del establecimiento y las malas condiciones de explotación.

Ante estas circunstancias, la Administración consideró la opción de acometer una actuación definitiva con el propósito de recuperar totalmente el conjunto. Collarte Rodríguez redactaba el nuevo proyecto de rehabilitación que, aunque no totalmente acorde con las previsiones del proyecto piloto, sí acataba su filosofía ${ }^{36}$. (Plano 2) Fue necesaria una nueva licitación para la explotación del establecimiento, que ahora adquiría la categoría de hotel-monumento de tres estrellas, siendo finalmente inaugurado en noviembre de 2004.

Durante las diversas fases de la rehabilitación, los distintos arquitectos intentaron garantizar la supervivencia de los valores del monumento y prepararlos para soportar futuras actuaciones y cambios de uso. Pretendieron que las pautas del proyecto fuesen capaces de compatibilizar las más actuales técnicas y materiales con los ya existentes, evitando en todo momento la mímesis formal y asegurando la reversibilidad de las actuaciones. El estado de ruina parcial del monasterio fue entendido como un valor añadido a la intervención: la propia ruina fue interpretada como una inversión del proceso de construcción del edificio. (Fig. 2) Así, ésta fue incluida como un elemento generador de un nuevo conjunto de valores espaciales conformados por perspectivas visuales insólitas, transparencias y superposiciones volumétricas que no serían posibles en su estado de construcción ideal.

Tras su conversión en hotel, Aciveiro recuperó su valor de referencia activa en la comarca de Terra de Montes, constituyéndose como polo generador de un proceso de desarrollo de las expectativas de futuro para el hábitat comarcal. Sin embargo, este hecho sólo favorece su supervivencia, pero no la garantiza, ya que su índice de ocupación apenas resulta rentable.

\section{San Clodio de Leiro (Leiro, Ourense)}

Enclavado en el fondo de un amplio valle surcado por el río Avia, el actual Hotel Monumento de San Clodio de Leiro se presenta como la conclusión de un debate existente a finales de los años noventa sobre sus posibles futuros usos.

Tras la desamortización, una de las pocas dependencias del monasterio que siguió en funcionamiento fue la botica. El resto del conjunto fue destinado a cuartel de la Milicia Nacional, circunstancia que evitó su venta hasta el año 1839, momento en el que se intentó vender la piedra del claustro regular. Finalmente, el

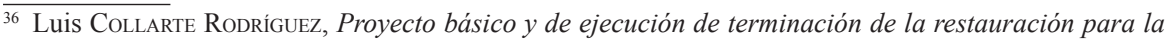
hospedería del monasterio de Acibeiro, Archivo de la Dirección Xeral de Patrimonio Cultural, referencia 2002/266. Incluye complementario (2003/386). A Coruña, 2002-2003.
} 


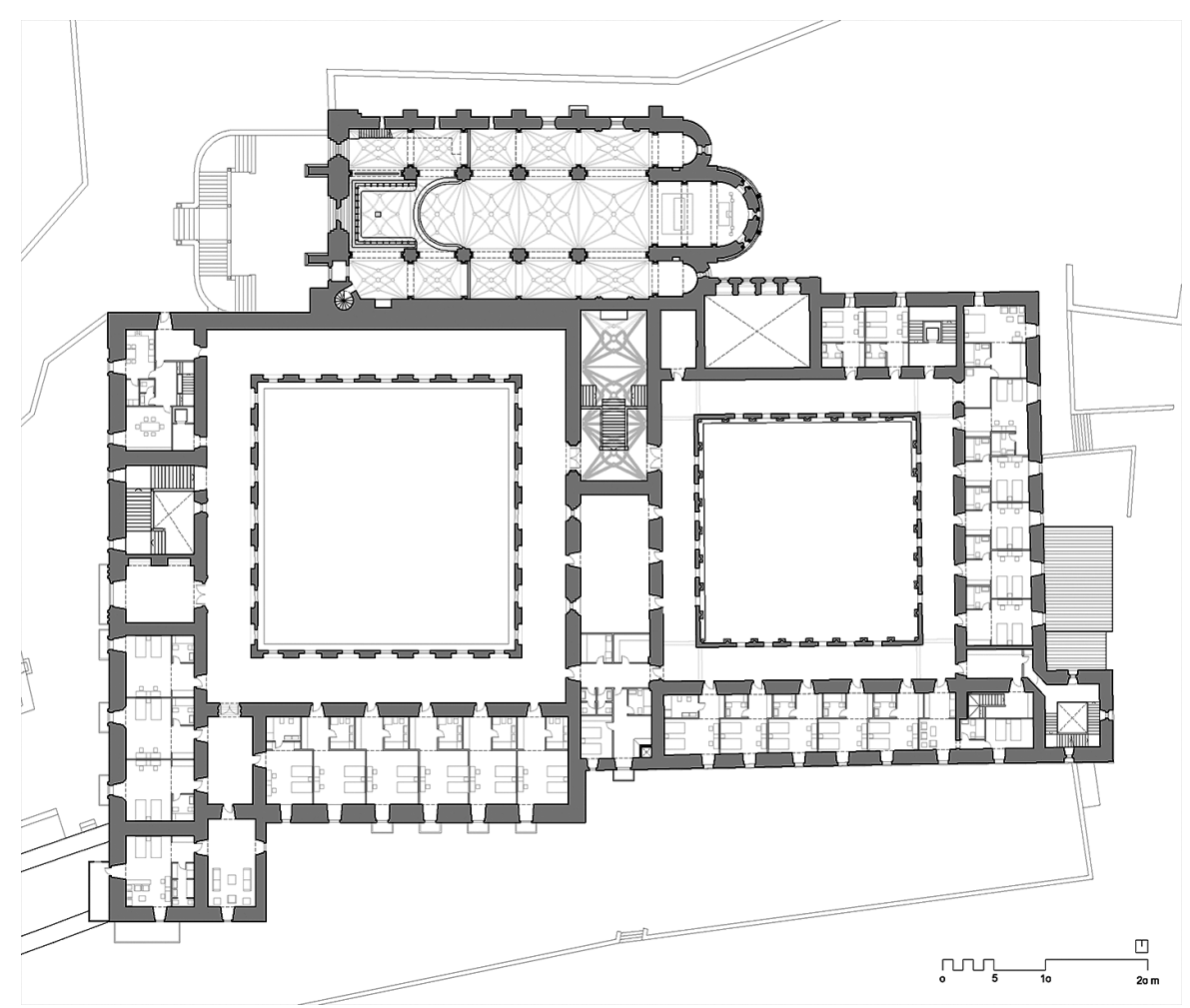

Plano 3. Planta primera de San Clodio de Leiro. En negro se señalan las obras realizadas para su conversión en establecimiento hotelero. (Planimetría elaborada por la autora)

ayuntamiento dispuso de las estancias que consideró necesarias para establecer el salón municipal, una escuela de primaria y la cárcel municipal. Pero a pesar de ello, el deterioro avanzó por toda la fábrica ${ }^{37}$.

Cuando fue declarado Monumento Nacional en 1981, el estado de ruina era preocupante: fue necesaria una intervención de urgencia -dirigida por Suances Pereiro- para estabilizar el conjunto ${ }^{38}$. Mientras, la Xunta de Galicia, el Obispado

\footnotetext{
${ }^{37}$ Entre otra bibliografía, para la historia de San Clodio podemos consultar: Ana Goy Diz, O mosteiro de San Clodio de Leiro. Ourense, Fundación Caixa Galicia, 2005. Antonio López Ferreiro, Compendio de la historia del monasterio de San Clodio del Ribeiro de Avia, Santiago de Compostela, 1895. Alberta LoRENZO ASPRES, "San Clodio de Leiro", en Intervencións no patrimonio galego para a industria hostaleira. A Coruña, Universidade da Coruña, 2014, págs. 407-444. Manuel LuCAS ÁLVAREZ, El monasterio de San Clodio do Ribeiro en la Edad Media: Estudio y documentos. Sada, Edicións O Castro, 1996.

38 Javier Suances Pereiro, Proyecto básico y de ejecución de obras de intervención en el monasterio de San Clodio en Leiro, Archivo de la Dirección Xeral de Patrimonio Cultural, referencia 1991/006. Ourense, 1990 .
} 

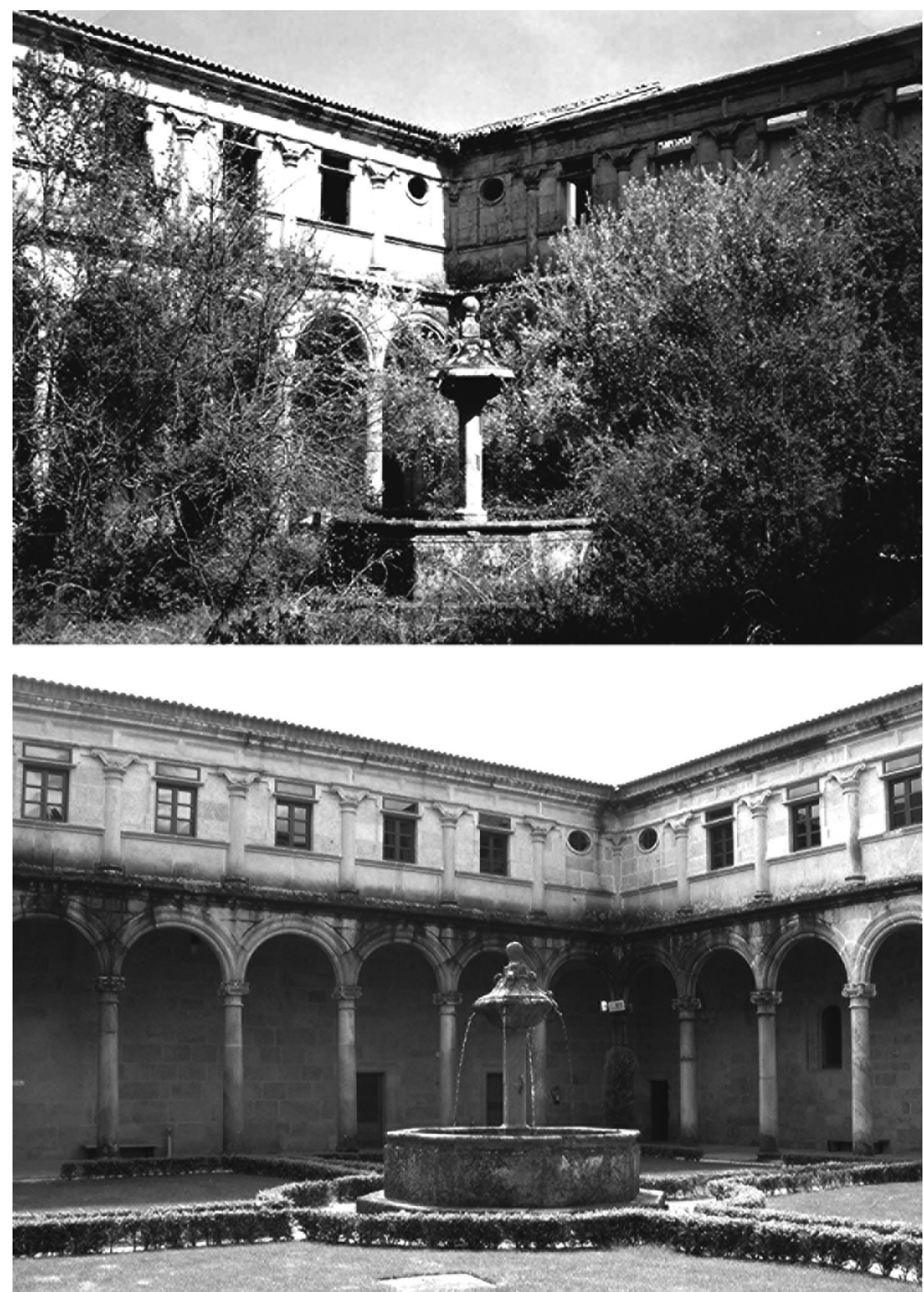

Fig. 3. Vista del claustro procesional de San Clodio de Leiro, antes (marzo 1991, Suances Pereiro) y después de su rehabilitación hotelera (diciembre 2013, Archivo fotográfico de la autora). 
de Ourense, la comunidad benedictina de Samos - propietaria de parte del monasterio- y el ayuntamiento de Leiro iniciaban una serie de diálogos para establecer las bases fundamentales que permitiesen la recuperación del cenobio. Estas conversaciones culminaron con el encargo de un estudio previo sobre las posibilidades de uso y adaptación que ofrecía el conjunto: como punto de partida estaba la instalación de una escuela de capacitación agraria, pero a medida que el acuerdo se iba concretando también lo hacía un nuevo programa de usos ${ }^{39}$.

Con las obras de consolidación avanzadas, se reconsideró el programa debido a la suposición de unos gastos tales a la Administración que en un momento determinado serían muy difíciles de sostener. Y apostando por una fórmula que asegurase su buena conservación y su autogestión se decidió dedicar San Clodio a una zona para el estudio del monumento y de su historia, y otra zona como hotel. El correspondiente proyecto estuvo finalizado en junio de 1998 por los arquitectos Bouzas Cavada y Martínez Quinteiro ${ }^{40}$. (Plano 3) Y a medida que se terminaba la actuación, la Xunta convocó un concurso para la explotación hotelera del cenobio dando entonces por inaugurado el establecimiento de cuatro estrellas.

La rehabilitación integral del edificio se ejecutó mediante soluciones respetuosas, austeras y reversibles con el objetivo de favorecer la convivencia entre las diferentes fases constructivas y los distintos estilos, manteniendo y subrayando la coherencia del conjunto ${ }^{41}$; hecho favorecido por la indecisión inicial sobre el nuevo uso. Sin despreciar el uso de materiales actuales o de técnicas constructivas más recientes, las soluciones tomadas se adaptaron a un edificio con reconocido valor patrimonial, quedando las obras ejecutadas subordinadas al mantenimiento y preservación de los valores culturales del monumento.

Los arquitectos también intentaron conservar -sin descuidar las exigencias del nuevo programa, pero sin sucumbir a ellas- la autenticidad de los espacios teniendo en cuenta el uso anterior de las estancias, obteniéndose de esta manera una mayor adecuación al nuevo programa. (Fig. 3) De esta forma no sólo no peligró la autenticidad de la arquitectura heredada, sino que se permitió la conservación de su identidad.

\footnotetext{
39 Ildefonso Estévez Martínez, Proyecto básico de rehabilitación de San Clodio de Leiro para escuela de capacitación agraria y otros usos, Archivo de la Dirección Xeral de Patrimonio Cultural, referencia 1991/028. Leiro, 1994.

${ }^{40}$ Manuel Bouzas CaVada y David Martínez Quinteiro, Proyecto básico y de ejecución de rehabilitación del monasterio de San Clodio do Ribeiro de Avia, Archivo de la Dirección Xeral de Patrimonio Cultural, referencia 1996/026. Incluye modificados (1998/091 y 1998/318) y obras complementarias (1998/184). Vigo, 1996-1998.

${ }^{41}$ M. Bouzas Cavada y D. Martínez Quinteiro, Proyecto básico y de ejecución... Memoria descriptiva.
} 


\section{San Vicente de O Pino (Monforte de Lemos, Lugo)}

En la actualidad, el conjunto monumental de San Vicente de O Pino -monasterio, pazo y torre- ${ }^{42}$ es el resultado de un proceso tortuoso y polémico que llegó a ser tratado en el Parlamento y sobre el que se abrió una investigación por parte de la Dirección Xeral de Patrimonio de la Xunta de Galicia, actuando la fiscalía de oficio para esclarecer la existencia de irregularidades en su rehabilitación ${ }^{43}$.

Con la desamortización de 1835 desapareció la vida claustral en San Vicente, convirtiéndose en centro hospitalario y en asilo de ancianos. Tras quedar vacío en 1919, fue cedido a la abadía de Samos, que envió monjes para que renovasen la vida regular ${ }^{4}$. Del conocido como pazo de los Condes de Lemos, algunos restos de la edificación primitiva sobrevivieron a la reconstrucción realizada por Beatriz de Castro tras el incendio de $1672^{45}$. Y la torre del Homenaje -considerada como la herencia más importante de la fortaleza monfortina- alberga actualmente en su interior una importante colección de fotografías y armaduras.

En los años noventa, la Xunta de Galicia perseguía la idea de convertir todo el conjunto monumental en un gran complejo turístico. Tras firmar los correspondientes convenios de colaboración y apoderamiento con la Casa de Alba y la comunidad religiosa, encargaba la redacción de un plan director al arquitecto Alonso Montero, quien elaboró un programa de actuaciones dirigidas a la salvaguarda y puesta en valor de todo el conjunto ${ }^{46}$. Al mismo tiempo, se llegaba a un acuerdo con el Instituto de Turismo de España y el Ministerio de Economía y Hacienda para su reutilización, de cuyo proyecto se encargó Fernández-Cuenca

\footnotetext{
42 Entre otra bibliografía, para la historia de San Vicente de O Pino podemos consultar: Manuel R. GARcía Álvarez, "En torno a los orígenes del Monasterio de San Vicente del Pino", Boletín de la Comisión Provincial de Monumentos Históricos y Artísticos de Lugo, 5, 37-38 (1952), págs. 80-90. Alberta LoRENZo AsPres, "San Vicente de O Pino", en Intervencións no patrimonio galego para a industria hostaleira. A Coruña, Universidade da Coruña, 2014, págs. 445-484. Luis Moure MARIÑo, Apuntes para la historia de Monforte de Lemos. Santiago de Compostela, Xunta de Galicia, 1997. Ramón Otero Pedrayo y Germán VÁzquez Rodríguez-Sueiro, Historia de Monforte y su Tierra de Lemos, León, Editorial Everest, 1990. José Manuel Pita Andrade, Monforte de Lemos, Santiago de Compostela, Bibliófilos Gallegos, 1952.

${ }^{43}$ Las primeras voces de alarma sobre el impacto de las obras de rehabilitación en el conjunto monfortino salieron de la Asociación de Amigos de la Muralla. El colectivo envió al presidente de la Xunta y al consejero de Cultura un exhaustivo informe en el que se denunciaban los daños producidos en el conjunto monumental por la construcción del parador. Según su criterio, la reforma del monasterio y del palacio condal ocasionaba atentados contra el patrimonio histórico-artístico que requerían la paralización inmediata de las obras. Véase "La obra del parador de Monforte causa destrozos en el conjunto monumental", La Voz de Galicia, 18 de marzo de 2002.

${ }_{44}$ Alberta LoRenzo Aspres, "San Vicente de O Pino", en Intervencións no patrimonio galego para a industria hostaleira, A Coruña, Universidade da Coruña, 2014, págs. 445-484.

45 José Manuel Pita Andrade, Monforte de Lemos, Colección Obradoiro, V. Santiago de Compostela, Bibliófilos Gallegos, 1952, págs. 31-49.

46 José María Alonso Montero, Plan director del monte de San Vicente do Pino en Monforte de Lemos, Archivo de la Dirección Xeral de Patrimonio Cultural, referencia 1998/271. Lugo, 1998.
} 


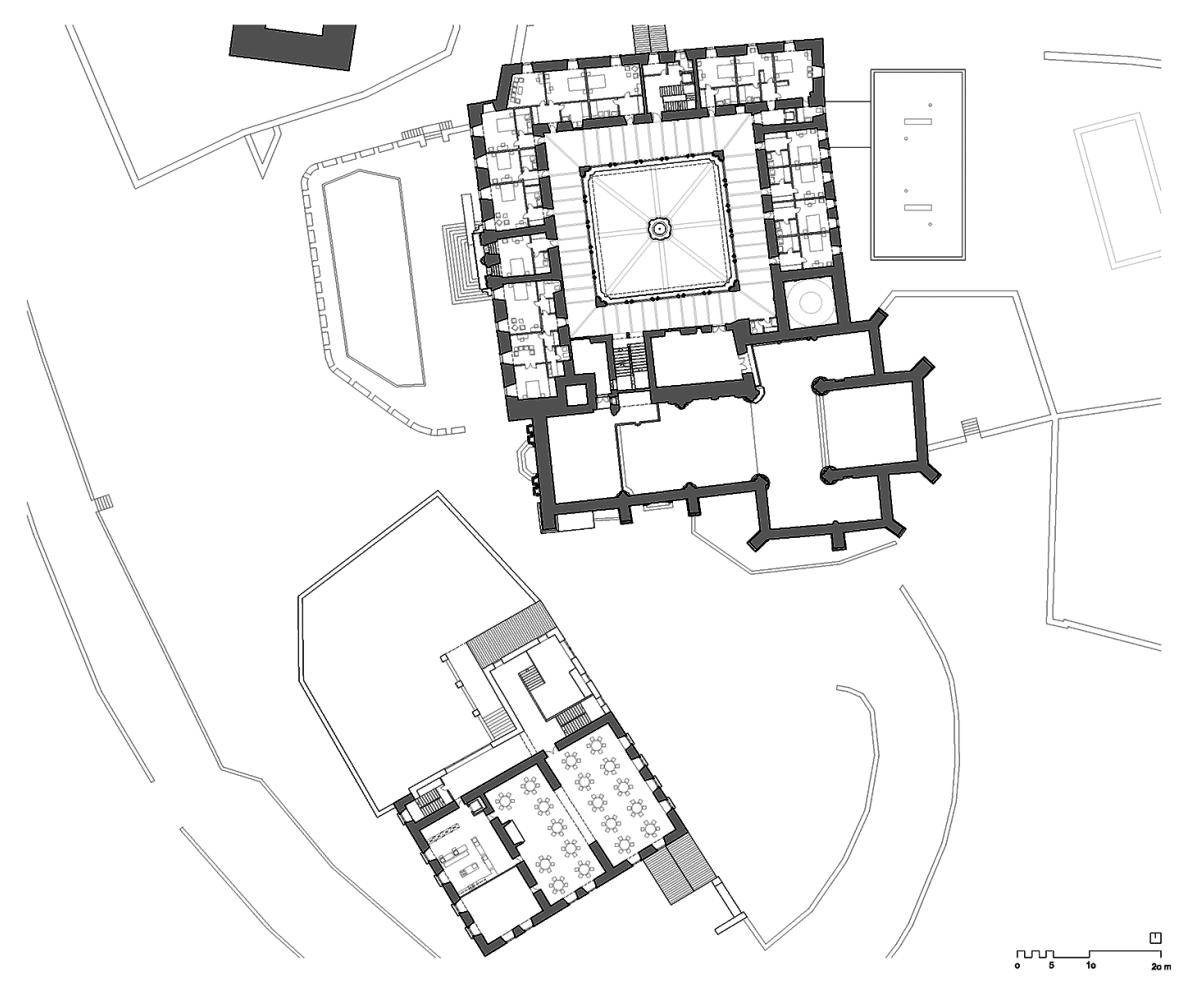

Plano 4. Planta general del conjunto monumental de San Vicente de O Pino.

En negro se señalan las obras realizadas para su conversión en establecimiento hotelero. (Planimetría elaborada por la autora)

Gómez a comienzos de 1999. Dos años después se aprobó el documento definitivo por parte de todas las autoridades competentes con la finalidad de alcanzar unas mejores soluciones que compaginasen la conservación de un legado histórico extraordinario con las necesidades funcionales que un establecimiento de la categoría de un parador requiere ${ }^{47}$. (Plano 4) Finalmente, la inauguración del parador tuvo lugar el 21 de julio de 2003.

Con todo, se realizó una rehabilitación total del conjunto mediante soluciones agresivas que afectaron gravemente a la autenticidad de la herencia arquitectónica. Usando materiales de larga tradición regional, se acometieron diversas actuaciones que siguieron las pautas de un diseño actual que marcase claramente las distintas épocas constructivas ${ }^{48}$. Sin embargo, este diseño contemporáneo aplicado en el

\footnotetext{
47 Carlos Fernández-Cuenca Gómez, Proyecto básico y de ejecución de Parador de Turismo en Monforte de Lemos, Archivo de la Dirección Xeral de Patrimonio Cultural, referencia 1999/263. Madrid, 2000.

${ }^{48}$ C. Fernández-Cuenca Gómez, Proyecto básico y de ejecución... Memoria descriptiva.
} 

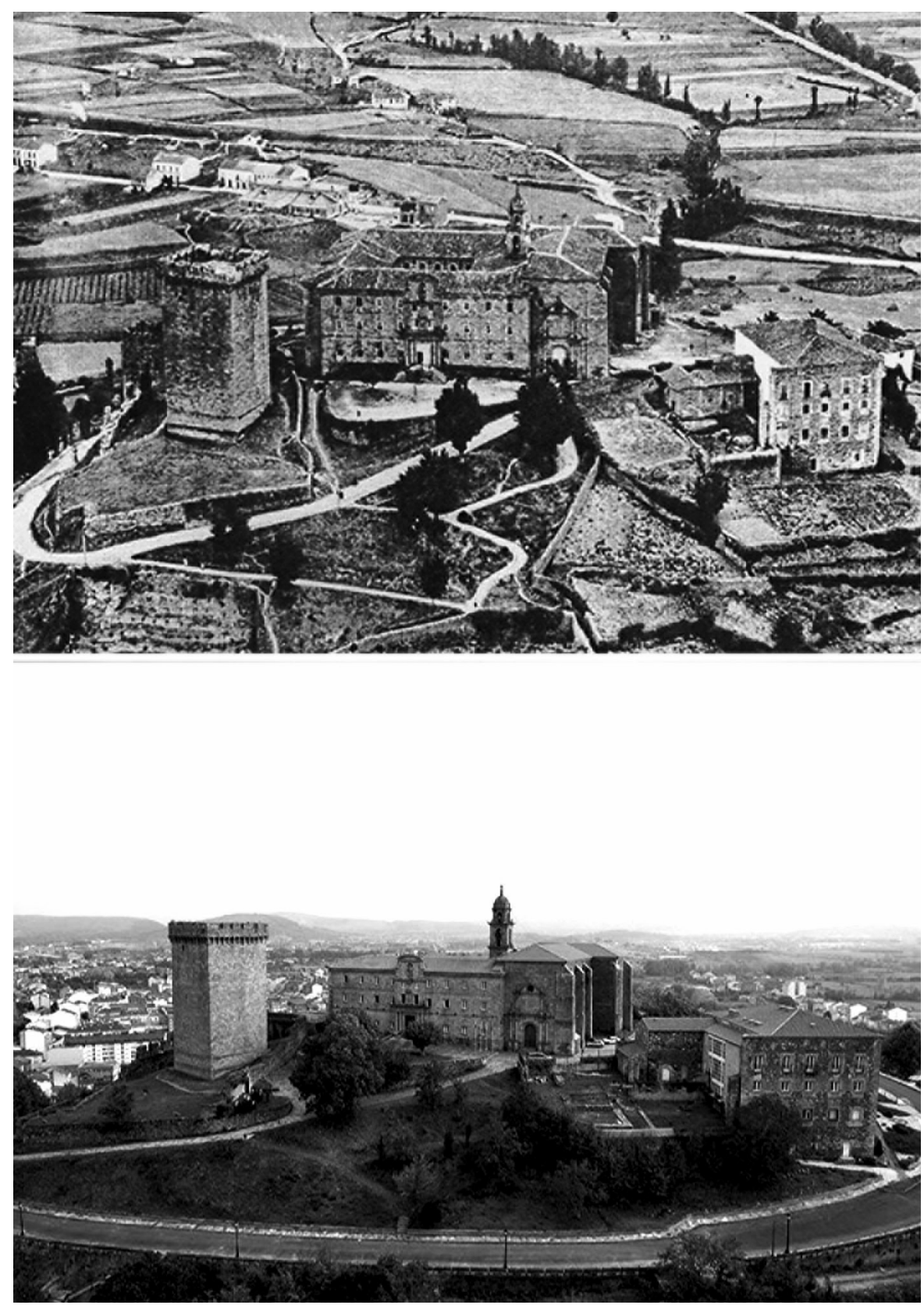

Fig. 4. Vista aérea del conjunto monumental antes (ca. 1952, Archivo fotográfico de la Real Academia Gallega de Bellas Artes) y después de su conversión en parador (ca. 2010, Archivo fotográfico del ayuntamiento de Monforte de Lemos). 

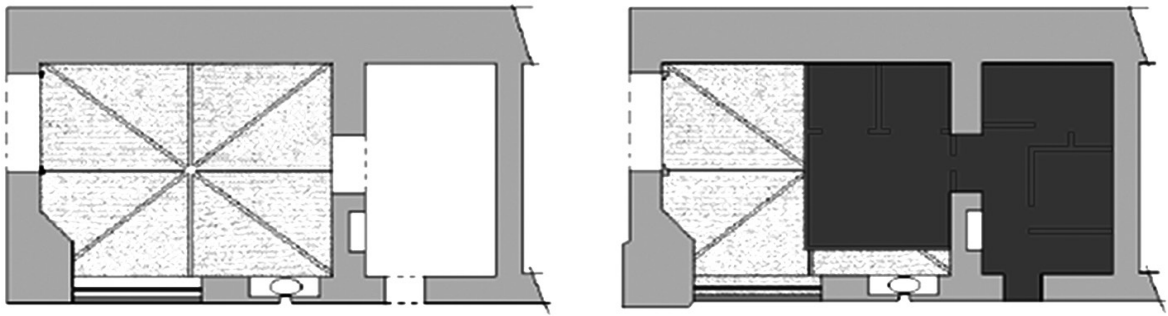

Plano 5. Esquema de la sacristía vieja y del oratorio abacial de San Vicente de O Pino, antes y después de su conversión en aseos para el parador. En línea negra discontinua representa la 'Puerta Regular' tapiada de acceso al claustro; la línea negra de puntos es la reja de madera original del siglo XVII; las líneas negras continuas son los nuevos tabiques.

(Reinterpretación de Carnero Rodríguez, 2007)

nuevo volumen que se construyó en el palacio condal pecó de exceso de tradición, llegando a producirse tal mimetismo con la fábrica existente que apenas se lograría distinguir lo nuevo de lo viejo. Se creó así una falsa visión de la historia constructiva del edificio, provocando una falsa unidad histórica que distorsionaría la percepción del conjunto monumental. (Fig. 4) Y en cuanto al nuevo volumen exento levantado junto al monasterio, a pesar de exhibir individualidad y fragmentación con respecto a la arquitectura preexistente, no obtuvo el resultado esperado: en cierto modo, contaminaría la visión del conjunto.

Tampoco se mantuvo el carácter reversible de las obras: esto supuso el sacrificio de irrepetibles elementos históricos en aras de una mayor funcionalidad. Así, por ejemplo, la sacristía vieja - que era junto con la fábrica de la iglesia la parte más antigua del monasterio- fue terriblemente modificada para albergar los aseos del parador $^{49}$ (Plano 5); o las escaleras de honor y del refectorio -cuya balaustrada permanecía abandonada en un sótano-, ambas neoclásicas y atribuidas a Ferro Caaveiro, fueron desmanteladas para la instalación de ascensores.

\section{San Francisco de Valdedeus (Santiago de Compostela, A Coruña)}

En la actualidad, el Hotel Monumento San Francisco es el resultado de la adición de diversas actividades que le aportan ese carácter de monumento vivo. Junto con el carácter religioso de la iglesia conventual y de la capilla de la Venerable Orden Tercera, este conjunto constituye el centro neurálgico de la Orden Franciscana Menor de la Provincia Franciscana de Santiago, de la que además de

\footnotetext{
49 A raíz de esta actuación, el oratorio abacial fue destruido en su totalidad con múltiples tabiques que supusieron la desaparición de toda la decoración pictórica mural. En César CARnERo Rodríguez, Informe patológico de la iglesia de San Vicente do Pino de Monforte de Lemos (Lugo): Fábrica y conjunto de bienes muebles, Archivo de la Dirección Xeral de Patrimonio Cultural, referencia 2007/331. Lugo, 2007.
} 
ser su sede administrativa, alberga el seminario, la escuela de misión, la biblioteca y el archivo provinciales, la residencia sanitaria y los museos de Tierra Santa y de Arte Sacra de la Provincia. Además, cumple con su labor benéfica a través del centro de acogida benéfico-asistencial Juan XXIII.

Sin embargo, su supervivencia subyace sobre la función económica del establecimiento hotelero, que se vio abocada a una optimización plena, absoluta y permanente de sus recursos. Y fue precisamente esa optimización la que trajo consigo una actividad de continua evolución en el interior del edificio con la intención de adaptarse a los nuevos tiempos y a las nuevas demandas, captando un mayor abanico de usuarios que, con sus ingresos, continuarían asegurando el futuro de la comunidad.

El deterioro de sus fábricas comenzó en agosto de 1835 con la emisión del decreto de exclaustración de los religiosos, por cuyo cumplimiento la comunidad se vio obligada a abandonar el inmueble, que fue posteriormente ocupado por varias familias. Ante el riesgo de que la iglesia se convirtiese en un depósito de pólvora, los exclaustrados abrieron de nuevo el templo al culto, cerrando materialmente toda comunicación entre la iglesia y el resto del edificio. En este estado permaneció durante más de veinte años, hasta que en enero de 1862 salió a subasta pública tras haber sido firmado el traslado del Colegio de Misiones para Tierra Santa y Marruecos. Fue entonces cuando se iniciaron las obras necesarias para conservar en el mejor estado posible las instalaciones del conjunto y adecuarlas a los nuevos usos y funciones necesarios para la supervivencia de los religiosos ${ }^{50}$.

En 1967 se decidió dedicar las habitaciones del Dormitorio Nuevo de la portería como residencia universitaria. Sin embargo, tras transcurrir más de diez años, ésta fue cerrada. Más tarde, entre 1984 y 1986 se acometió el acondicionamiento de las habitaciones para su nuevo uso como hostal -según el proyecto de los arquitectos Campanero García y Costa Buján- con el objetivo de incorporar el convento a la vida de la ciudad de una forma más intensa ${ }^{51}$.

En torno al cambio de siglo, el estudio formado por Alonso Fernández y Castro Nieto redactó el Plan Director del convento. En él destacaban -entre otros aspectos- la transcendencia económica de la hospedería en el sentido de que toda

\footnotetext{
${ }^{50}$ Entre otra bibliografía, para la historia de San Francisco de Valdedeus podemos consultar: Pedro Alonso FernándeZ y Francisco CASTro Nieto, Plan director del convento de San Francisco en Santiago de Compostela, Archivo de la Dirección Xeral de Patrimonio Cultural, referencia 2002/083. Vigo, 2001. Manuel de Castro y Castro, La provincia franciscana de Santiago. Ocho siglos de historia, Santiago de Compostela, Liceo Franciscano, 1983. Alberta Lorenzo Aspres, "San Francisco de Valdedeus", en Intervencións no patrimonio galego para a industria hostaleira, A Coruña, Universidade da Coruña, 2014, págs. 525-570.

51 Arturo Campanero García y Pablo Costa Buján, Proyecto básico de reforma interior del ala oeste del convento de San Francisco, Archivo de la Dirección Xeral de Patrimonio Cultural, referencia 1984/056. Santiago de Compostela, 1984.
} 


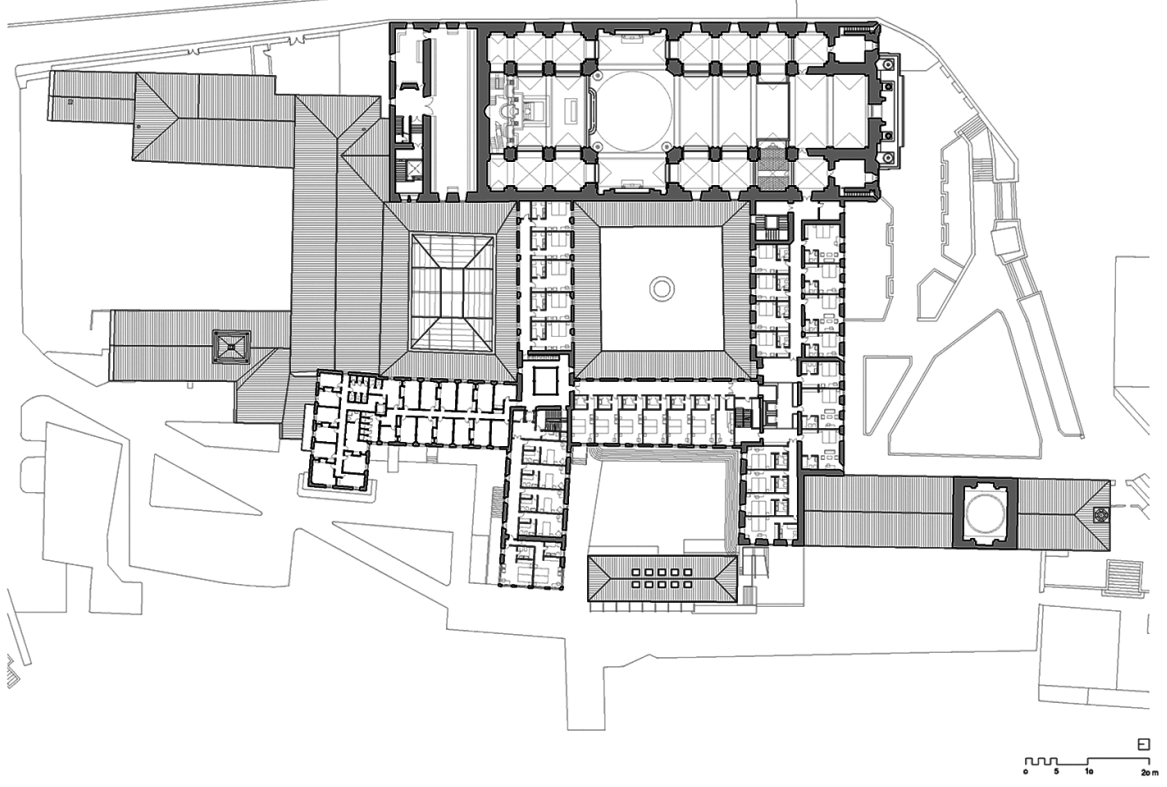

Plano 6. Planta segunda de San Francisco de Valdedeus. En negro se señalan las obras realizadas para su conversión en establecimiento hotelero. (Planimetría elaborada por la autora)

la supervivencia del monumento dependía de las aportaciones económicas derivadas de su explotación ${ }^{52}$. En consecuencia, elaboraron un proyecto para adecuar las instalaciones y las dependencias de la hospedería a los requerimientos de la normativa y legislación sectorial vigentes, al tiempo que se elevaba el nivel y la categoría turística de la misma. (Plano 6)

La conversión del convento en hotel no puede verse como una única intervención transformadora, sino como el resultado de una evolución natural en la propia historia del monumento y en las funciones que éste ha desempeñado y desempeña a lo largo de su vida. Por lo tanto, se debe partir de la transformación del hostal en un hotel de lujo, entendiéndola como una actuación que afectó principalmente a una redistribución de los espacios y a sus acabados, siendo totalmente respetuosa con el monumento. (Fig. 5)

Aprovechando estas obras, se mejoraron diversas celdas que habían quedado obsoletas y que no alcanzaban los parámetros mínimos de habitabilidad exigidos.

\footnotetext{
${ }^{52}$ Pedro Alonso Fernández y Francisco Castro Nieto, Plan director del convento de San Francisco en Santiago de Compostela, Archivo de la Dirección Xeral de Patrimonio Cultural de la Xunta de Galicia, referencia 2002/083. Vigo, 2001.
} 


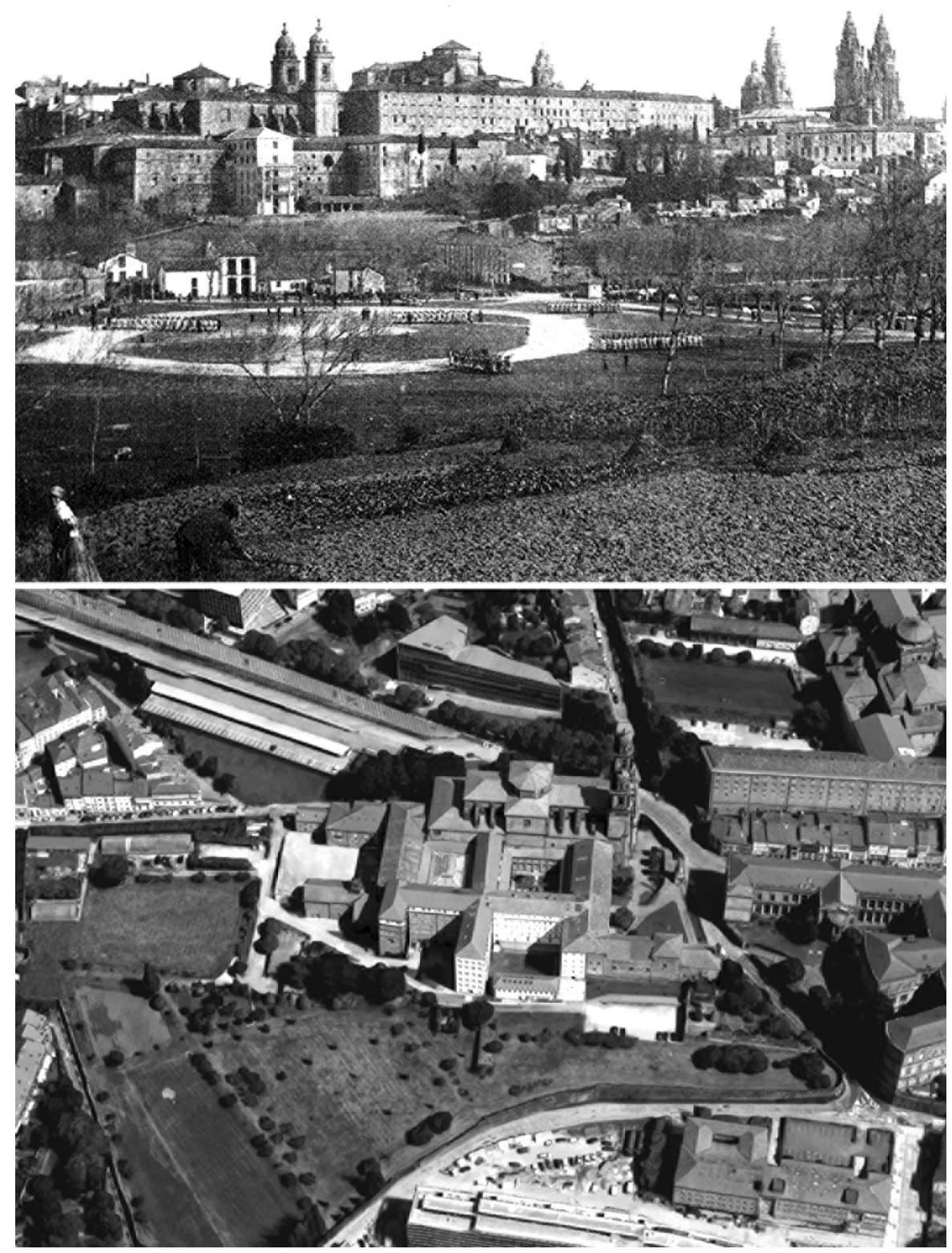

Fig. 5. Vista de San Francisco de Valdedeus antes y después de su transformación hotelera (Archivo municipal de Santiago de Compostela) 
Y dado que la adecuación de las habitaciones de la hospedería a la legislación del momento reducía el número de habitaciones para mantener las ratios de rentabilidad del nuevo hotel, se propuso la ampliación del mismo en la última planta del ala situada entre los claustros. Por otra parte, se rehabilitó la pequeña edificación anexa al convento para albergar la zona deportiva y las instalaciones técnicas necesarias del nuevo establecimiento, respectándose estrictamente sus características fundamentales.

\section{Resultados y Conclusiones}

Mediante el análisis de estos monumentos religiosos rehabilitados como establecimientos hoteleros en Galicia hemos comprobado cómo el abandono del inmueble supone el inicio de su inevitable ruina, demostrándose que la opción de un nuevo uso se ha presentado como la mejor garantía para su supervivencia, entendiendo este acto desde la capacidad del monumento de estar vivo y de participar en la sociedad del momento.

Con la excepción del conjunto monfortino, las intervenciones estudiadas destacaron el respecto por la autenticidad arquitectónica heredada: con la intención de convivir con diferentes fases constructivas de diversos estilos, manteniendo y resaltando la coherencia de los conjuntos, se respetaron los valores originales de los monumentos.

Sin descuidar las exigencias del nuevo programa, las actuaciones tomaron la preexistencia como punto de partida para el proyecto, resultando un refuerzo del carácter monumental de estas edificaciones; si bien es cierto que la tipología monacal presenta una mayor compatibilidad con el uso hotelero que otras posibles tipologías. Simplificando en gran medida la reutilización: las grandes zonas de entrada y recibimiento son empleadas como posibles zonas nobles del hotel, y la organización de múltiples estancias linealmente estructuradas con respecto a las zonas principales son destinadas a dormitorios para los futuros huéspedes.

En definitiva, la recuperación del Patrimonio para la industria hotelera se presenta como una garantía de su salvaguarda y autosuficiencia, aumentando además su plazo de vida y conformando un capítulo más de su historia: la rehabilitación supone la puesta en valor del monumento y permite su reintroducción en la vida activa de la sociedad sin alejarse de la idea implícita de objeto de recuerdo y mera contemplación. Y dicho monumento acaba por desempeñar un importante papel activo en la localidad donde se ubica, ya que además de crear empleo facilita el crecimiento económico de la zona.

Por otro lado, la industria turística ha pasado de ser un fenómeno de erosión y degradación de los recursos patrimoniales a un nuevo mecenas capaz de tutelar 
y financiar singulares elementos de nuestra herencia arquitectónica -en muchas ocasiones con una importante ayuda pública-.

Pero estas actividades rehabilitadoras, si se quiere que realmente sirvan para los fines para los que se conciben, es necesario que se planifiquen, coordinen y proyecten cuidadosamente en función de la demanda existente, pues llegará el momento en que en lugar de tener monumentos vacíos tendremos hoteles vacíos.

\section{BIBLIOGRAFÍA}

Alonso Fernández, Pedro y Castro Nieto, Francisco, Plan director del convento de San Francisco en Santiago de Compostela, Archivo de la Dirección Xeral de Patrimonio Cultural, referencia 2002/083. Vigo, 2001.

Alonso Montero, José María, Plan director del monte de San Vicente do Pino en Monforte de Lemos, Archivo de la Dirección Xeral de Patrimonio Cultural, referencia 1998/271. Lugo, 1998.

Bayón Mariné, Fernando (dir.), 50 años del turismo español. Un análisis histórico y estructural, Madrid, Centro de Estudios Ramón Areces, 1999.

Bouzas Cavada, Manuel y Martínez Quinteiro, David, Proyecto básico y de ejecución de rehabilitación del monasterio de San Clodio do Ribeiro de Avia, Archivo de la Dirección Xeral de Patrimonio Cultural, referencia 1996/026. Incluye modificados (1998/091 y 1998/318) y obras complementarias (1998/184). Vigo, 1996-1998.

Campanero García, Arturo y Costa Buján, Pablo, Proyecto básico de reforma interior del ala oeste del convento de San Francisco, Archivo de la Dirección Xeral de Patrimonio Cultural, referencia 1984/056. Santiago de Compostela, 1984.

Cano Lasso, Julio, de la Joya, Rafael y Moreno Barberá, Fernando, "Hostal de los Reyes Católicos en Santiago de Compostela", Revista Nacional de Arquitectura, 156 (1954), págs. 3-24.

Carnero Rodríguez, César, Informe patológico de la iglesia de San Vicente do Pino de Monforte de Lemos (Lugo): Fábrica y conjunto de bienes muebles, Archivo de la Dirección Xeral de Patrimonio Cultural, referencia 2007/331. Lugo, 2007.

Castro y Castro, Manuel de, La provincia franciscana de Santiago. Ocho siglos de historia, Santiago de Compostela, Liceo Franciscano, 1983.

Castro Fernández, Belén M., Francisco Pons - Sorolla y Arnau, Arquitecto - Restaurador: Sus Intervenciones en Galicia (1945-1985), Tesis doctoral, Santiago de Compostela, Facultad de Geografía e Historia, 2008.

Collarte Rodríguez, Luis, Proyecto básico y de ejecución de terminación de la restauración para la hospedería del monasterio de Acibeiro, Archivo de la Dirección Xeral de Patrimonio Cultural, referencia 2002/266. Incluye complementario (2003/386). A Coruña, 2002-2003.

Duro Peña, Emilio, El monasterio de San Esteban de Ribas de Sil, Orense, Instituto de Estudios Orensanos Padre Feijoo, 1977.

Duro Peña, Emilio y José Platero Paz, Historia, arte y entorno del Monasterio de Ribas de Sil, Ourense, Caixa Ourense, 1990.

Eslava Galán, Juan y Ontañón, Francisco, Paradores históricos, Barcelona, Lunwerg Editores, 1997. 
Estévez Martínez, Ildefonso, Proyecto básico de rehabilitación de San Clodio de Leiro para escuela de capacitación agraria y otros usos, Archivo de la Dirección Xeral de Patrimonio Cultural, referencia 1991/028. Leiro, 1994.

Fernández Fuster, Luis, Introducción a la teoría y técnica del turismo, Madrid, Alianza Editorial, 1989.

Fernández-Cuenca Gómez, Carlos, Proyecto básico y de ejecución de Parador de Turismo en Monforte de Lemos, Archivo de la Dirección Xeral de Patrimonio Cultural, referencia 1999/263. Madrid, 2000.

Fontenla Sanjuan, Concepción, "San Esteban de Ribas de Sil en el origen de la restauración actual en Galicia. Polémica y restauración, Loggia, 7 (1999), págs. 20-27.

Freixedo Alemparte, Alfredo y Suances Pereiro, Javier, Proyecto básico y de ejecución de rehabilitación del monasterio de San Esteban de Ribas de Sil para uso hotelero, Archivo de la Dirección Xeral de Patrimonio Cultural, referencia 1999/216. Incluye fase posterior (2000/015). Ourense, 2000.

Freixedo Alemparte, Alfredo; Suances Pereiro, Javier y Vecoña Pérez, Manuel, Proyecto básico y de ejecución de obras de intervención en el monasterio de San Esteban de Ribas de Sil, Archivo de la Dirección Xeral de Patrimonio Cultural, referencia 1986/011. Incluye reformados (1988/016) y fases posteriores (1989/015). Ourense, 1986.

García Álvarez, Manuel Rubén, "En torno a los orígenes del Monasterio de San Vicente del Pino", Boletín de la Comisión Provincial de Monumentos Históricos y Artísticos de Lugo, 5, 37-38 (1952), págs. 80-90.

González Moreno-Navarro, Antonio, "De la reutilización indiscriminada al uso sensato de los monumentos", en VIII Cursos Monográficos sobre el Patrimonio Histórico, Reinosa, Universidad de Cantabria, 1997, págs. 281-299.

Goy Diz, Ana, O mosteiro de San Clodio de Leiro, Ourense, Fundación Caixa Galicia, 2005.

"La obra del parador de Monforte causa destrozos en el conjunto monumental", La Voz de Galicia, 18 de marzo de 2002.

Lavaur, Luis, “Turismo de entreguerras (1919-1939)”, Estudios Turísticos, 68 (1980), págs. 3-36.

López Ferreiro, Antonio, Compendio de la historia del monasterio de San Clodio del Ribeiro de Avia, Santiago de Compostela, 1895.

Lorenzo Aspres, Alberta, Intervencións no patrimonio galego para a industria hostaleira, A Coruña, Universidade da Coruña, 2014.

Lucas Álvarez, Manuel, El monasterio de San Clodio do Ribeiro en la Edad Media: Estudio $y$ documentos, Sada, Edicións O Castro, 1996.

Manzano Monis, Julián L., Osuna Fajardo, José y Valverde Viñas, Jesús, Proyecto de consolidación y reforma del Hospital de Santiago de Compostela para su adaptación a Parador de Turismo y Albergue de Peregrinos. Archivo Histórico Universitario de Santiago de Compostela, legajo 1952-1971. Madrid, 1952.

Méndez Forte, Rosa, "El monasterio de San Esteban de Ribas de Sil", en La conservación de los monumentos arquitectónicos de Galicia (1840-1940), Ferrol, Émbora Editorial, 2010, págs. 568-581.

Menéndez Robles, María Luisa, El Marqués de la Vega Inclán y los orígenes del turismo en España, Madrid, Secretaría General de Turismo, 2006. 
Moure Mariño, Luis, Apuntes para la historia de Monforte de Lemos, Santiago de Compostela, Xunta de Galicia, 1997.

Muñoz Cosme, Alfonso, La conservación del patrimonio arquitectónico español, Madrid, Instituto de Conservación y Restauración de Bienes Culturales, Madrid, 1989.

Nogales Basarrate, Trinidad, "Parador Vía de la Plata. Mérida", Revista de Arqueología, 98 (1989), págs. 46-68.

Otero Pedrayo, Ramón y Germán Vázquez Rodríguez-Sueiro, Historia de Monforte y su Tierra de Lemos, León, Editorial Everest, 1990.

Pellejero Martínez, Carmelo, "La promoción del turismo en España durante la primera mitad del siglo XX: el papel del Estado”, Información Comercial Española, 730 (1994), págs. 127-146.

Pita Andrade, José Manuel, Monforte de Lemos, Santiago de Compostela, Bibliófilos Gallegos, 1952 (Colección Obradoiro, V).

"Qué es un Parador Museo", Paradores, 23 (2009), págs. 5-9.

Radio Televisión Española, Nuevo Parador Nacional 'Casa del Barón': una realización de la Dirección General de Turismo en Pontevedra, Galicia. Documento consultado en la Filmoteca Española, con la referencia NOT N 629 A. Madrid, 1955.

Rivera Blanco, Javier, "El debate sobre la pertinencia de los nuevos usos en la reciente historia de la restauración”, en VIII Cursos Monográficos sobre el Patrimonio Histórico, Reinosa, Universidad de Cantabria, 1997, págs. 263-277.

Rivera Blanco, Javier, De varia restauratione, Madrid, Abada, 2008.

Rodríguez Abilleira, Jaime, Proxecto piloto para a rehabilitación integral do Mosteiro de Acibeiro. Forcarei - Terra de Montes, Archivo de la Dirección Xeral de Patrimonio Cultural, referencia 1992/163. Pontevedra, 1992.

Rodríguez Fraíz, Antonio, O mosteiro de Aciveiro. Terra de Montes, Pontevedra, Diputación de Pontevedra, 2005.

Seoane López, Luis, “Una hospedería de lujo”, Galicia Emigrante, 4 (1954), pág. 1.

Suances Pereiro, Javier, Proyecto básico y de ejecución de obras de intervención en el monasterio de San Clodio en Leiro, Archivo de la Dirección Xeral de Patrimonio Cultural, referencia 1991/006. Ourense, 1990.

Ulled Merino, Antonio, La recuperación de edificios históricos para usos turísticos. La experiencia española, Madrid, Tecniberia, 1986.

Vaquero Díaz, Beatriz, "Fontes documentais para o estudio do Mosteiro de Santa María de Acibeiro do Arquivo da Catedral de Ourense", en II Congreso Internacional sobre el Císter en Galicia y Portugal, Ourense, Xunta de Galicia, 1999, págs. 951-994.

Vázquez Núñez, Arturo, "El monasterio de Ribas de Sil", Boletín de la Comisión Provincial de Monumentos Históricos y Artísticos de Orense, 15 (1900), págs. 261-280. 
